\title{
Global Simulation of Dust Aerosol with a Chemical Transport Model, MASINGAR
}

\author{
Taichu Y. TANAKA ${ }^{1,2}$ and Masaru CHIBA ${ }^{1}$ \\ 1. Meteorological Research Institute, Tsukuba, Japan \\ 2. JST Cooperative System for Supporting Priority Research \\ (Manuscript received 30 July 2004, in final form 10 February 2005)
}

\begin{abstract}
We have developed a dust aerosol module integrated into a global aerosol transport model, called MASINGAR (Model of Aerosol Species IN the Global AtmospheRe). The dust module treats dustemission processes based on the saltation-bombardment theory. A global soil texture database is used to determine the size distribution of parent soils. Erodibility factors for vegetation cover, snow cover, landuse type, and soil type are considered. Dry and wet deposition processes are dependent on particle size.

To obtain a climatological global dust emission, deposition, and spatial distribution, we performed a 25-year simulation which is assimilated to the 1979-2003 condition, using a nudging scheme. The simulated annual mean global emission flux and atmospheric dust load (with $0.2 \leq D \leq 20 \mu \mathrm{m}$ ) are 2149

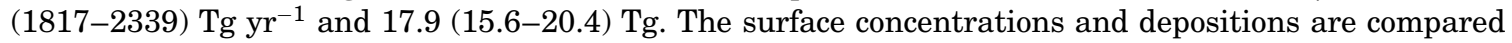
with observed data, and the dust emission flux is compared with previous model studies. The model reproduces the simulated seasonal variation of dust concentration at stations near East Asian dust sources, where most previous models have underestimated the amounts and amplitudes. The global simulation results indicate that the quantitative estimation of the dust budget is sensitive to the size distribution of the emitted dust.
\end{abstract}

\section{Introduction}

Mineral dust in the atmosphere has attracted increasing attention in recent years. Mineral dust plays several roles in the Earth's atmospheric environment, with regard to the radiation budget (Tegen and Fung 1994; Andreae 1996), biogeochemical cycles (Martin and Fitzwater 1988; Martin 1991; Swap et al. 1992), and atmospheric chemistry (Dentener et al. 1996; Wang et al. 2002; Martin et al. 2003). It can also affect visibility and human health. In order to study the climatic roles of dust, a global-scale dust model is necessary.

It has been pointed out that the atmospheric dust load has been increased by human activities. Tegen and Fung (1995) estimated that

Corresponding author: Taichu Y. Tanaka, Meteorological Research Institute, 1-1 Nagamine, Tsukuba, Ibaraki, Japan

Email: yatanaka@mri-jma.go.jp

(C) 2005, Meteorological Society of Japan
$30 \%$ to $50 \%$ of atmospheric dust is emitted from soils disturbed by human activity, although recent research by Tegen et al. (2004) suggests that agricultural areas contribute less than $10 \%$ to the dust load and that the effects of climate change will dominate the changes in dust emissions. A report from the Intergovernmental Panel on Climate Change (IPCC) (Penner et al. 2001) estimates that radiative forcing by mineral dust originating from anthropogenic activities ranges from -0.6 to $+0.4 \mathrm{~W} \mathrm{~m}^{-2}$, although an accurate estimate cannot be assigned yet. This large uncertainty is due to deficiencies in the estimation of dust distribution and also of its radiative properties (Sokolik and Toon 1999). Recent modeling studies estimate that the global dust-emission flux falls within a range from less than 1000 to $3000 \mathrm{Tg}^{-1}$ (Penner et al. 2001) and that the atmospheric dust load ranges from 15 to $35 \mathrm{Tg}$.

A global dust model requires appropriate parameters for dust emission to create a link 
between the microphysical scale and the largegrid scale. Dust emission by wind erosion has been studied using wind tunnel experiments and field studies (e.g., Gillette 1978; Gillette and Passi 1988; Shao et al. 1993). In largescale atmospheric models, meteorological and ground-surface conditions are available only on coarse grid scales. One of the challenges in mineral dust research is to represent sub-grid scale wind erosion processes realistically at large-scale model resolutions, typically on the order of more than $100 \mathrm{~km}$. Tegen et al. (2002) pointed out that although it is recognized that recent dust models can reproduce first-order patterns of dust distributions, oversimplification of the treatment of dust emission within these models has introduced errors in dust transport and deposition. The incorporation of an improved dust-emission scheme is necessary to reduce uncertainties in the estimation of dust distribution.

Recent studies have pointed out that surface properties of the ground are important for understanding dust emission. Dust emission by wind erosion is a complicated process that involves many meteorological and surface conditions, such as surface wind speed, snow cover, soil moisture, soil texture, and land-use type. Liu and Westphal (2001) showed that the calculation of dust emission was improved by using the friction velocity instead of the surface wind speed. Kurosaki and Mikami (2004) demonstrated the importance of snow cover and its effects on dust emission. Any global dustemission model must successfully incorporate the effects of these ground-surface properties.

Our first-generation global dust aerosol module for use with the Model of Aerosol Species IN the Global AtmospheRe (MASINGAR) was developed and described in Tanaka et al. (2003). This model has been used by the Japan Meteorological Agency (JMA) for operational dust forecasting. The model uses very simple parameterization for dust emission and does not consider atmospheric stability (friction velocity), variations in threshold friction velocity, or differences in soil properties. In this paper, we present a description of our second-generation dust module, as incorporated in MASINGAR. The dust module is intended to be physically based as much as possible. In Section 2, we describe the physical processes of the dust module in detail. In Section 3, we compare and discuss our simulated global and station-based results with available observations that include dust concentration and deposition. We conclude with a summary of this paper in Section 4 .

\section{Model description}

\subsection{Model framework}

In this work we used MASINGAR, which is a global three-dimensional chemical transport model for tropospheric aerosol. It includes four major aerosol species: nss-sulfate, carbonaceous, mineral dust, and sea-salt aerosols (Tanaka et al. 2003). The atmospheric part of the model is called the MRI/JMA 98 atmospheric general circulation model (AGCM), which is a spectral AGCM developed by the Meteorological Research Institute (MRI) and JMA (Shibata et al. 1999). The AGCM includes a land-surface model called SiB (Simple Biosphere). Atmospheric dynamical fields (horizontal and vertical winds, air pressure, air temperature, relative humidity, precipitation, cloud fraction, and convective mass flux) and ground-surface properties (soil moisture, snow cover, leaf area index, surface temperature, surface winds, and roughness length) are coupled with the aerosol transport model. Table 1 lists the specifications for MASINGAR. The transport processes of the model are described in Appendix A.

The model has a built-in four-dimensional data assimilation system with a nudging

Table 1. Specification of the aerosol transport model, MASINGAR.

\begin{tabular}{|c|c|}
\hline Atmospheric model & MRI/JMA 98 AGCM \\
\hline Tracer transport & 3-D semi-Lagrangian \\
\hline Vertical diffusion & $\begin{array}{l}\text { Mellor-Yamada level-2 } \\
\text { closure }\end{array}$ \\
\hline Convective transport & $\begin{array}{l}\text { Mass flux by Arakawa- } \\
\text { Schbert moist } \\
\text { convection scheme }\end{array}$ \\
\hline Horizontal resolution & $\begin{array}{l}\left.\mathrm{T} 21 \text { (about } 5.6^{\circ} \times 5.6^{\circ}\right) \\
\sim \mathrm{T} 106(\text { about } \\
\left.1.1^{\circ} \times 1.1^{\circ}\right)\end{array}$ \\
\hline Vertical resolution & $\begin{array}{l}\sigma-p \text { hybrid } 30 \text { layers } \\
\quad(\text { surface }-0.8 \mathrm{hPa})\end{array}$ \\
\hline Temporal resolution & Variable (5-20 minutes) \\
\hline Data assimilation & $\begin{array}{l}\text { Newtonian relaxation } \\
\text { scheme }\end{array}$ \\
\hline
\end{tabular}


scheme, which enables the model to perform realistic simulation of a specific period and provide forecasts of dust distribution for a few days. The assimilation system is described in Appendix B.

\subsection{Dust emission}

The mineral dust module uses a size-bin method to transport discrete, non-interacting dust size classes realistically. The size range and number of the size-bins are freely configurable. Observed dust particles have diameters ranging from 0.2 to $100 \mu \mathrm{m}$ (Duce 1995). Because of gravitational settling, particles larger than $20 \mu \mathrm{m}$ have short lifetimes and are not subject to long-range transport. The current model is therefore restricted to particles ranging from 0.2 to $20 \mu \mathrm{m}$ in diameter. The transported dust particles are logarithmically divided into 10 size classes. Table 2 presents the size range and volume mean diameter for each size-bin. The mass densities of the dust particles are taken from the density of quartz $\left(2.65 \mathrm{~g} \mathrm{~cm}^{-3}\right)$, which is the most common mineral found on the surface of the Earth.

Dust emission generated by wind erosion is initiated when the friction velocity over an erodible surface exceeds a threshold value, which is determined by several ground-surface conditions. The first step of the dust-emission scheme is to predict the friction velocity suitable for dust emission and the threshold friction velocity. Three mechanisms can be identified for dust emission: (1) direct entrainment of dust particles by aerodynamic forces, (2) release of dust particles as saltating particles

Table 2. Size range and volume mean diameter $\left(D_{v}\right)$ for each size-bin of the dust aerosol module.

\begin{tabular}{ccc}
\hline Size bin & Diameter range $\mu \mathrm{m}$ & $D_{v} \mu \mathrm{m}$ \\
\hline 1 & $0.200-0.317$ & 0.271 \\
2 & $0.317-0.502$ & 0.430 \\
3 & $0.502-0.796$ & 0.681 \\
4 & $0.796-1.26$ & 1.08 \\
5 & $1.26-2.00$ & 1.71 \\
6 & $2.00-3.17$ & 2.71 \\
7 & $3.17-5.02$ & 4.30 \\
8 & $5.02-7.96$ & 6.81 \\
9 & $7.96-12.6$ & 10.8 \\
10 & $12.6-20.0$ & 17.1 \\
\hline
\end{tabular}

strike the surface causing an abrasion event, and (3) disintegration of dust coats on sand grains and clay aggregates during saltation (Shao 2000). The first mechanism, direct aerodynamic entrainment of dust, is an order of magnitude less important than the dust emission caused by the other mechanisms (Shao et al. 1993) and hence it is not included in the module. The other two mechanisms, which are referred to as saltation-bombardment, are considered to be responsible for dust emission. The second step is to predict these saltation events and their intensity, because saltationbombardment indirectly involves the saltation of sand particles as an intermediate process. The mass flux of saltation particles $(\boldsymbol{Q})$ can be converted to a vertical mass flux of dust particles $(F)$.

The mass flux of dust emission from the $i$-th size-bin $\left(\Delta F_{i}\right)$ supplied to the lowest model layer is calculated as

$$
\Delta F_{i}=C A \Delta F_{i 0},
$$

where $\Delta F_{i 0}$ is the dust-emission flux estimated by the wind erosion model, $A$ is the erodible areal fraction of the grid determined from the ground-surface conditions, and $C$ is a global tuning factor. The final form of $\Delta F_{i 0}$ is presented in Section 2.2.d. The erodible areal fraction $A$ is assumed to be expressed by the following factorial form,

$$
A=\left(1-A_{v}\right)\left(1-A_{s}\right)\left(1-A_{w}\right) A_{l} A_{t},
$$

where $A_{v}, A_{s}, A_{w}, A_{l}$, and $A_{t}$ represent the factors of vegetation cover, snow cover, water cover, land-use type, and soil type. The factors $A_{v}, A_{w}, A_{s}, A_{l}$, and $A_{t}$ are described in Section 2.2.f. The factor $C$ is chosen to give a reasonable climatological total dust-emission flux. In this case it was set to $C=1 \times 10^{-3}$, which was determined to yield an annual global source strength of about $2100 \mathrm{Tg} \mathrm{yr}^{-1}$ (Penner et al. 2001).

\section{a. Friction velocity for dust emission}

The intensities of saltation and dust emission depend on the surface friction stress caused by atmospheric turbulence through friction velocity $u_{*}$. Therefore, it is necessary to calculate the friction velocity carefully.

We considered two roughness lengths with respect to dust emission from erodible surfaces 
(Marticorena and Bergametti 1995; Zender et al. 2003a). The first is the aerodynamic roughness length, which includes non-erodible, obstacle elements such as pebbles, rocks, and vegetation. This is traditionally known as the roughness length for momentum transfer, $z_{0 m}$. The value of $z_{0 m}$ is calculated within the landsurface model $(\mathrm{SiB})$ in the AGCM. We first calculate the wind speed at $10 \mathrm{~m}$ height $\left(U_{10}\right)$ from the wind speed of the lowest model layer $\left(U_{L}\right)$. Assuming a logarithmic vertical wind profile and neutral atmospheric stability conditions, $U_{10}$ is expressed as

$$
U_{10}=U_{L} \frac{\ln \left(10 / z_{0 m}\right)}{\ln \left(Z_{1} / z_{0 m}\right)}
$$

where $Z_{1}$ is the height of the middle point of the lowest model layer (about $40 \mathrm{~m}$ ). When $z_{0 m}$ increases due to obstacles such as vegetation cover, $U_{10}$ decreases.

The second roughness length is the "smooth" roughness length, which is the roughness length of a surface composed of potentially erodible particles without any non-erodible elements, $z_{0 s}$ (Marticorena and Bergametti 1995). Since it is difficult to determine the roughness length over the grid scale of the global model, we used a constant value, $z_{0 s}=0.3 \mathrm{~mm}$, which is a value typical for sand deserts (Takeuchi and Kondo 1981). With $z_{0 s}, u_{* s}$ is calculated from $U_{10}$ as

$$
u_{* s}=\frac{\kappa U_{10}}{\ln \left(10 / z_{0 s}\right)} \sqrt{G_{m}},
$$

where $\kappa$ is the von Kármán's constant, and $G_{m}$ is the function of atmospheric stability (Jacobson 1999).

\section{b. Threshold friction velocity}

The threshold friction velocity $u_{* t}$ is determined by the particle size and the characteristics of the ground surface, such as soil moisture, salt, organic materials, and surface crusting. A practical approach to account for the impact of particle size and surface conditions on $u_{* t}$ is to express it in the following factorial form

$$
u_{* t}=u_{* t}(D, w)=u_{* t 0}(D) f_{w}(w),
$$

where $u_{* t 0}(D)$ is the threshold friction velocity for sand particles of size $D$ in an idealized situation; namely, when the soil is dry, bare, and free of crust and salt. In this model, only the dependences on particle size and soil moisture $\left(f_{w}\right)$ are considered because of the lack of available global databases for other surface properties.

The threshold friction velocity for soil particles in the idealized situation, $u_{* t 0}$, has been analyzed by several researchers (e.g., Bagnold 1941; Greeley and Iversen 1985; Shao and Lu 2000). We adopted the semi-empirical formulation of $u_{* t 0}$ proposed by Shao and Lu (2000),

$$
u_{* t 0}(D)=\sqrt{A_{N}\left(\frac{\rho_{p} g D}{\rho_{a}}+\frac{\Gamma}{\rho_{a} D}\right)},
$$

where $g$ is the gravitational acceleration, $\rho_{a}$ is the air density, $\rho_{p}$ is the particle density, $A_{N}=0.0123$, and $\Gamma=3 \times 10^{-4} \mathrm{~kg} \mathrm{~s}^{-2}$. The last two are empirical parameters determined from wind-tunnel experiments (Shao and Lu 2000). Under typical meteorological conditions, the minimum value of $u_{* t 0}$ is about $0.2 \mathrm{~m} \mathrm{~s}^{-1}$ at $D \sim 100 \mu \mathrm{m}$.

Soil moisture increases the cohesive force among soil particles, and thus increases the threshold friction velocity for soil particles. The parameterization of Fécan et al. (1999) is applied to calculate the effect of soil moisture on $u_{* t 0}, f_{w}$,

$$
f_{w}= \begin{cases}1 & w \leq w_{r} \\ \sqrt{1+a\left[100\left(w-w_{r}\right)\right]^{b}} & w>w_{r}\end{cases}
$$

where $w$ is the gravimetric soil water content, and $w_{r}$ is the threshold gravimetric soil water content. The parameters $a$ and $b$ are empirical constants and were set to $a=1.21$, and $b=0.68$. The parameterization of Fécan et al. (1999) was found to be consistent with in situ observations in the Taklimakan desert (Ishizuka et al. 2005). To calculate $w_{r}$, we again followed the parameterization of Fécan et al. (1999),

$$
w_{r}=0.17 M_{\text {clay }}+0.14 M_{\text {clay }}^{2},
$$

where $M_{\text {clay }}$ is the mass fraction of clay in the soil. The soil water content $w$ is calculated from the output of the uppermost layer of the $\mathrm{SiB}$ land-surface model of the AGCM. Because the output of $\mathrm{SiB}$ is a volumetric soil water concentration $\theta$ with a unit of $\mathrm{m}^{3} \mathrm{~m}^{-3}$, it is necessary to convert it to the gravimetric water content $w$ $\left(\mathrm{kg} \mathrm{kg}^{-1}\right.$ ) used in Eq. (7). For the conversion, we 
followed the method of Zender et al. (2003a). This scheme assumes that the volumetric water content of the soil at saturation, $\theta_{s}$ $\left(\mathrm{m}^{3} \mathrm{~m}^{-3}\right)$, equals the porous volume of air in dry soil. Using this assumption, the equivalence between $\theta$ and $w$ is

$$
\begin{aligned}
& \theta_{s}=0.489-0.126 M_{\text {sand }} \\
& \rho_{b, d}=\rho_{p}\left(1-\theta_{s}\right) \\
& w=\theta \rho_{l} / \rho_{b, d},
\end{aligned}
$$

where $\rho_{l}=1000 \mathrm{~kg} \mathrm{~m}^{-3}$ is the density of liquid water, $\rho_{b, d}\left(\mathrm{~kg} \mathrm{~m}^{-3}\right)$ is the bulk density of dry soil, and $M_{\text {sand }}$ is the mass fraction of sand in the soil. $M_{\text {clay }}$ and $M_{\text {sand }}$ are given by the global soil texture database of Webb et al. (2000) (see Section 2.2.e).

\section{c. Streamwise saltation flux}

The mass flux of saltating particles $\tilde{Q}\left(D_{s}\right)$ is calculated using a formula from Owen (1964)

$\tilde{\boldsymbol{Q}}\left(\boldsymbol{D}_{s}\right)= \begin{cases}\frac{c_{s}\left(\boldsymbol{D}_{s}\right) \rho_{a} u_{* s}^{3}}{g}\left(1-\frac{u_{* t}\left(\boldsymbol{D}_{s}\right)^{2}}{u_{* s}^{2}}\right) & u_{* s}>u_{* t} \\ 0 & u_{* s} \leq u_{* t}\end{cases}$

where

$$
c_{s}\left(D_{s}\right)=0.25+\frac{V_{s}\left(D_{s}\right)}{3 u_{* s}},
$$

where $V_{s}\left(D_{s}\right)$ and $u_{* t}\left(D_{s}\right)$ are the gravitational settling velocity (Eq. 22) and the threshold friction velocity (Eq. 5) of a saltating particle of diameter $D_{s}$, respectively, and $u_{* s}$ is the smooth friction velocity (Eq. 4). Equation (12) was derived for soils with uniform particle size, but is widely used to fit observed sand transport.

\section{d. Vertical dust flux}

Assuming that saltation-bombardment is the primary process for dust emission, the vertical flux $\tilde{F}_{0}$ of particles of size $D_{d}$ can be assumed to be proportional to the saltation flux

$$
\tilde{F}_{0}\left(D_{d}, D_{s}\right)=\alpha\left(D_{d}, D_{s}\right) \tilde{\mathbf{Q}}\left(D_{s}\right),
$$

where the coefficient $\alpha$ is called the sandblasting mass efficiency and is generally expressed as a function of the saltation particle size $D_{s}$, the size of the vertically emitted particle $D_{d}$, and the threshold friction velocity $u_{* t}$. From Eq. (14), the vertical dust-emission flux within the $i$-th particle size range $\left[D_{i}, D_{i+1}\right]$ is expressed as

$$
\begin{aligned}
\Delta F_{i 0}= & \int_{D i}^{D i+1} \int_{0}^{\infty} \alpha\left(D_{d}, D_{s}\right) \tilde{\boldsymbol{Q}}\left(D_{s}\right) \\
& \times p\left(D_{s}\right) d D_{s} p\left(D_{d}\right) d D_{d}
\end{aligned}
$$

where $p$ is the size distribution of the parent soil particles.

Many large-scale numerical dust models set $\alpha$ as a constant value, or use the relationship suggested by Marticorena and Bergametti (1995) (e.g., Woodward 2001; Lunt and Valdes 2002; Zender et al. 2003a). However, there are some difficulties with this scheme. First, the size distribution of the emitted dust particles has to be predetermined. Secondly, the scheme depends only on the clay fraction of the soil, with the dust flux increasing exponentially with the clay fraction. Considering the uncertainty in the existing soil texture databases, this dependency might lead to serious errors in the estimated dust flux.

We adopted instead the energy-based dustemission model proposed by Shao et al. (1996) for calculating $\alpha$. This scheme, which predicts the size distribution of the dust-emission flux, is based on theoretical considerations and wind-tunnel experiments. Although it has been applied to some regional dust models (Shao et al. 1996; Shao and Leslie 1997), no application to global dust models has been reported. Following Shao et al. (1996), the sandblasting mass efficiency is calculated as

$$
\alpha=\frac{2}{3} \frac{\rho_{p}}{\rho_{a}} \frac{\beta_{1}\left(D_{s}\right) \beta_{2}\left(D_{d}\right) \gamma}{u_{* t}\left(D_{d}\right)^{2}},
$$

where $\beta_{1}, \beta_{2}$, and $\gamma$ are empirically determined parameters. Following Shao et al. (1996), $\gamma \sim 2.5$, and $\beta_{1}$ and $\beta_{2}$ appear as functions of $D_{s}$ and $D_{d}$,

$$
\begin{aligned}
& \beta_{1}\left(D_{s}\right)=0.125 \times 10^{-4} \ln \left(D_{s}\right)+0.328 \times 10^{-4} \\
& \beta_{2}\left(D_{d}\right)=\exp \left(-140.7 D_{d}+0.37\right) .
\end{aligned}
$$

From Eqs. (12), (14), and (16), the vertical flux within the size range $\left[D_{i}, D_{i+1}\right]$ is

$$
\begin{aligned}
\Delta F_{i 0}= & \frac{2}{3} \frac{\rho_{p} \gamma}{\rho_{a}} \int_{D i}^{D i+1} \frac{\beta_{2}\left(\boldsymbol{D}_{d}\right)}{u_{* t}\left(\boldsymbol{D}_{d}\right)^{2}} p\left(\boldsymbol{D}_{d}\right) d \boldsymbol{D}_{d} \\
& \times \int_{0}^{\infty} \beta_{1}\left(\boldsymbol{D}_{s}\right) \tilde{\boldsymbol{Q}}\left(\boldsymbol{D}_{s}\right) p\left(\boldsymbol{D}_{s}\right) d \boldsymbol{D}_{s} .
\end{aligned}
$$


Equation (19) is integrated over the soil particle-size distribution, which is divided logarithmically into 32 discrete sections ranging from 20 to $1000 \mu \mathrm{m}$.

\section{e. Soil particle size distribution}

Soil is primarily characterized by its particlesize distribution, contents and depth. The dustemission scheme described in the previous section requires a known particle-size distribution for a parent soil. However, measured soil particle-size distributions are not available on the global scale. Therefore, we have to make some assumptions to generate a soil particlesize distribution from available soil texture databases.

For this work, we used the global soil texture database of Webb et al. (2000). This database specifies the percentage of sand $(D \geq 50 \mu \mathrm{m})$, silt $(2<D<50 \mu \mathrm{m})$, and clay $(D \leq 2 \mu \mathrm{m})$ for individual soil horizons. The data have a horizontal resolution of $1^{\circ} \times 1^{\circ}$ and 15 soil horizons. In this model, data from the uppermost soil horizon is used, since the conditions for dust emission generally occur only at the surface.

To create a continuous soil particle size distribution from the global soil texture database, we assumed that the distribution can be expressed by a tri-modal lognormal probability density function. This is similar to the method used by Lunt and Valdes (2002). The soil particle-size distribution is expressed as

$$
\frac{d M(D)}{d \log D}=\sum \frac{M_{i}}{\sqrt{2 \pi} \sigma_{i}} \exp \left(-\frac{\left(\log \left(D / \tilde{D}_{i}\right)\right)^{2}}{2 \sigma_{i}^{2}}\right),
$$

where the mode $i$ is for sand, silt, or clay. $M_{i}$ is the mass fraction of the $i$-th mode, taken from the database of Webb et al. (2000). The parameters $\tilde{D}_{i}$ and $\sigma_{i}$ are set to $\tilde{D}_{\text {sand }}=300 \mu \mathrm{m}$, $\tilde{D}_{\text {silt }}=10 \mu \mathrm{m}, \tilde{D}_{\text {clay }}=0.5 \mu \mathrm{m}, \sigma_{\text {sand }}=1.0, \sigma_{\text {silt }}=$ 1.4 , and $\sigma_{\text {clay }}=1.4$. The mode diameter $\tilde{D}_{i}$ is determined to be a representative size for each mode. The geometric standard deviation $\sigma_{i}$ is chosen to be large enough that the three modes are connected continuously, but small enough that overlap of the modes does not become too large and so that the resulting distributions are similar to the measured particle-size distributions (e.g., Shao 2000). This determination is somewhat subjective, and we are planning a sensitivity study of these parameters to evaluate its uncertainties.
In natural soils, small particles may exist as soil aggregates or be attached to sand particles. During a minor wind erosion event, the soil aggregates and sand particles with dust coating behave like sand particles. In an intense wind erosion event, these aggregates and dust coatings disintegrate and release dust into the air (Shao 2000). As a result, the soil particle-size distribution changes with the intensity of wind erosion. Therefore, the soil particle-size distributions taken at rest (in situ) and those taken under disturbed conditions must be distinguished. The database of Webb et al. (2000) has a relatively large portion of the clay fraction (Zender et al. 2003a), and probably provides mass fractions under fully disturbed conditions. However, we do not address the changes of the soil particle-size distribution under disturbed soil conditions, since there is very little quantitative information available on the global scale.

\section{f. Erodible areal fraction}

\section{(1) Effect of vegetation cover}

Vegetation cover decreases the area of erodible surface and reduces the friction velocity on the bare ground $\left(u_{* s}\right)$ around and beneath the vegetation cover. The drag force of the vegetation cover is related to the height, shape, and type of vegetation. For simplicity, the areal fraction of the bare ground, in which the dust emission is suppressed by the vegetation, is assumed to be proportional to the leaf area index (LAI),

$$
A_{v}= \begin{cases}\frac{\mathrm{LAI}}{\mathrm{LAI}_{t}} & \mathrm{LAI}<\mathrm{LAI}_{t} \\ 1 & \mathrm{LAI} \geq \mathrm{LAI}_{t}\end{cases}
$$

where $\mathrm{LAI}_{t}$ is the threshold value of LAI. Currently, we set a globally constant value of $\mathrm{LAI}_{t}=1.2$, after Lunt and Valdes (2002). The LAI is calculated using the $\mathrm{SiB}$ land-surface model, which uses a monthly averaged LAI database from Wilson and Henderson-Sellers (1985). The monthly averaged LAI value is interpolated, and updated at one-day intervals.

\section{(2) Effect of snow cover and surface ice}

Snow cover and surface ice effectively suppress dust emission (Kurosaki and Mikami 2004). The dust-emission flux is assumed to be linearly reduced with the areal fraction of snow cover $A_{s}$ in the grid. The snow cover fraction 
is prognostically calculated using the $\mathrm{SiB}$ landsurface model, and updated at each time-step.

\section{(3) Effect of water cover}

The areal fraction of inland water (oceans, rivers, and lakes) in the model grid, $A_{w}$, is predetermined and is time-invariant. $A_{w}$ is calculated from the $200 \mathrm{~m} \times 200 \mathrm{~m}$ resolution U.S. Geological Survey database (USGS; http:// info.er.usgs.gov/) by averaging the inlandwater fraction over the model grid.

\section{(4) Land-use database}

The $1^{\circ} \times 1^{\circ}$ resolution land-use database from DeFries and Townshend (1994) is used to locate the potential erodible land-use types. The land-use types of broadleaf evergreen forest and coniferous evergreen forest are removed from the potential erodible surface, so for these land-use types, $A_{l}=0$.

\section{(5) Soil-type database}

We used the soil-type dataset from Zobler (1986), which divides the soil into 106 types, with a horizontal resolution of $1^{\circ} \times 1^{\circ}$. The soiltype "lithosol" is excluded as a possible dust source, because it consists of hard rocks from the mountainous regions, according to Tegen and Fung (1995). The soil-type erodibility factor is $A_{t}=0$ for lithosol, and $A_{t}=1$ for other soil types.

\subsection{Removal processes}

\section{a. Gravitational settling and dry deposition}

We calculate the gravitational settling velocity $V_{s}$ assuming that the particles are spherical. Ginoux (2003) investigated the effect of nonsphericity on mineral dust modeling and suggested that the inclusion of non-sphericity in the treatment of sedimentation will not significantly improve the results of global dust models. $V_{s}$ is expressed as

$$
V_{s}=\sqrt{\frac{4 g C_{c}\left(\rho_{p}-\rho_{a}\right) D^{2}}{3 C_{D} \rho_{a}}},
$$

where $D$ is the diameter of the particle, $C_{c}$ is the Cunningham slip-flow correction, and $C_{D}$ is the drag coefficient. The Cunningham slip-flow correction $C_{c}$ is expressed as

$$
C_{c}=1+\mathrm{Kn}[A+B \exp (-C / \mathrm{Kn})],
$$

where $\mathrm{Kn}$ is the Knudsen number, and the coefficients $A, B$, and $C$ are set to $1.257,0.4$, and 1.1 (Jacobson 1999), respectively. The drag co- efficient $C_{D}$ is given by Morsi and Alexander (1972).

At the ground surface, aerosol particles are removed by dry deposition. Dry deposition is calculated using the resistance analog model, which expresses dry deposition velocity as the inverse of the sum of resistances (Seinfeld and Pandis 1997). The dry deposition velocity $v_{d}$ of dust particles is expressed as

$$
v_{d}=\frac{1}{r_{a}+r_{b}+r_{a} r_{b} V_{s}}+V_{s},
$$

where $r_{a}$ is the aerodynamic resistance, and $r_{b}$ is the quasi-laminar resistance. The aerodynamic resistance $r_{a}$ is a function of the atmospheric stability, surface wind speed, and roughness. It is independent of particle size. In contrast, the quasi-laminar resistance $r_{b}$ depends on the particle size, and is calculated as

$$
r_{b}=\frac{1}{u_{*}\left(\mathrm{Sc}^{2 / 3}+10^{-3 / \mathrm{St}}\right)},
$$

where $u_{*}$ is the friction velocity, $\mathrm{Sc}$ is the Schmidt number, and St is the Stokes number (Seinfeld and Pandis 1997).

\section{b. Wet deposition}

Wet deposition consists of in-cloud and below-cloud scavenging. For in-cloud scavenging by large-scale and convective precipitation, we used the parameterization developed by Giorgi and Chameides (1986). The in-cloud scavenging rate of dust aerosol is calculated using the first-order loss rate

$$
\left(\frac{\partial \chi}{\partial t}\right)_{\mathrm{IC}}=-\Lambda_{\mathrm{IC}} \chi
$$

where $\chi$ is the mixing ratio of the dust, and $\Lambda_{\mathrm{IC}}$ is the in-cloud scavenging loss rate. The loss rate $\Lambda_{\mathrm{IC}}\left(\mathrm{s}^{-1}\right)$ due to in-cloud scavenging is expressed by

$$
\Lambda_{\mathrm{IC}}=\frac{F_{c}\left(1-\exp \left(-\beta_{c} T_{c}\right)\right)}{\Delta t},
$$

where $F_{c}$ is the fraction of the cloud in which the precipitation occurs, $T_{c}$ is the duration of the precipitation within the model time-step, and $\beta_{c}$ is the frequency of conversion from cloud water to rain water. The parameters $F_{c}$ and $\beta_{c}$ are calculated from the rainwater formation rate and cloud amount, generated by the AGCM. 
The below-cloud scavenging is calculated as

$$
\left(\frac{\partial \chi}{\partial t}\right)_{\mathrm{BC}}=-\lambda_{\mathrm{BC}} P \chi
$$

where $P$ is the precipitation intensity, and $\lambda_{\mathrm{BC}}$ is the below-cloud scavenging coefficient. For the calculation of the below-cloud scavenging coefficient, the collision efficiency between dust particles and raindrops, $E$, is considered. $E$ is calculated as the sum of the efficiencies for Brownian diffusion, interception, and inertial impaction. The expressions for each term were proposed by Slinn (1984) and given by Seinfeld and Pandis (1997) as

$$
\begin{aligned}
& E\left(D_{p}, D_{d}\right)=\frac{4}{\operatorname{Re~Sc}} \\
& \times\left(1+0.4 \operatorname{Re}^{1 / 2} \mathrm{Sc}^{1 / 3}+0.16 \operatorname{Re}^{1 / 2} \mathrm{Sc}^{1 / 2}\right) \\
& +4 \frac{D_{d}}{D_{p}}\left[\omega^{-1}+\frac{D_{d}}{D_{p}}\left(1+2 \mathrm{Re}^{1 / 2}\right)\right] \\
& +H\left(\mathrm{St}-\mathrm{St}^{*}\right)\left(\frac{\rho_{l}}{\rho_{p}}\right)^{1 / 2}\left(\frac{\mathrm{St}-\mathrm{St}^{*}}{\mathrm{St}-\mathrm{St}^{*}+2 / 3}\right)^{3 / 2}
\end{aligned}
$$

where $H(x)$ is the Heaviside step function, $D_{d}$ is the diameter of the dust particle, $D_{p}$ is the raindrop diameter, Re is the Reynolds number of the raindrop, Sc is the Schmidt number of the dust particle, St is the Stokes number of the dust particle, and $\omega=\mu_{l} / \mu_{a}$ is the viscosity ratio between water and air. $\mathrm{St}^{*}$ is the critical Stokes number, which is defined as

$$
\mathrm{St}^{*}=\frac{1.2+\frac{1}{12} \ln (1+\mathrm{Re})}{1+\ln (1+\mathrm{Re})}
$$

The below-cloud scavenging coefficient is expressed as

$\lambda_{\mathrm{BC}}\left(D_{d}\right)=\frac{\frac{\pi}{4} \int_{0}^{\infty} D_{p}^{2} V_{g, p}\left(D_{p}\right) E\left(D_{p}, D_{d}\right) N\left(D_{p}\right) d D_{p}}{P}$,

where $V_{g, p}\left(D_{p}\right)$ and $N\left(D_{p}\right)$ are the terminal velocity and the number concentration for raindrops, respectively.

In practice, $\lambda_{\mathrm{BC}}$ is set to a globally constant value for each size-bin for computational efficiency. For the calculation of the collision efficiency, the raindrop size distribution is set to be the globally uniform Marshall-Palmer dis-

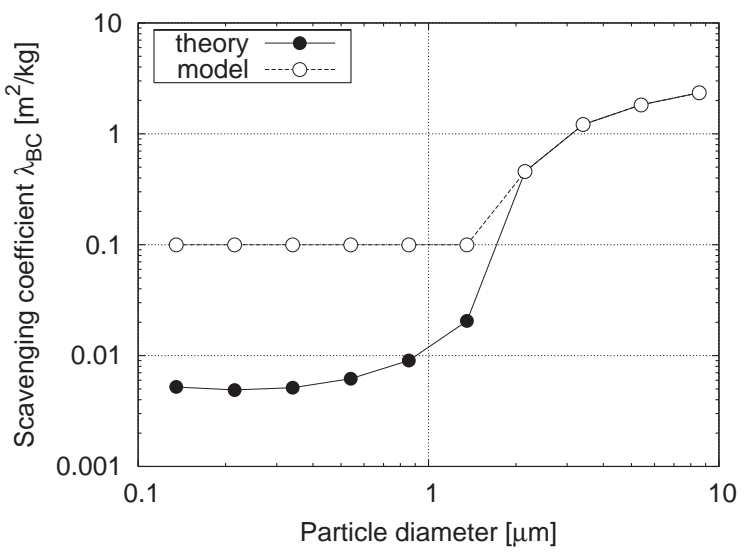

Fig. 1. Scavenging coefficient $\lambda_{\mathrm{BC}}$ as a function of dust size. Filled circles represent theoretical values, and open circles represent the values used in the model.

tribution,

$$
N\left(D_{p}\right)=N_{0} \exp \left(\Psi D_{p}\right),
$$

where $D_{p}$ is the raindrop size in $\mathrm{mm}, N_{0}=$ $7000 P^{0.37} \mathrm{~m}^{-3} \mathrm{~mm}^{-1}, \psi=3.8 P^{-0.14} \mathrm{~mm}^{-1}$, and $P$ is in $\mathrm{mm} \mathrm{hr}^{-1}$ (Seinfeld and Pandis 1997). For simplicity, we calculate Eq. (31) by setting $P$ to a constant value of $0.1 \mathrm{~mm} \mathrm{hr}^{-1}$. The resultant value of $\lambda_{\mathrm{BC}}$ is shown in Fig. 1 . We set the lower limit for the scavenging coefficient to 0.1 because using an extremely small scavenging coefficient for particles of $D<2 \mu \mathrm{m}$ appears to result in an unrealistically long lifetime for these particles. Zender et al. (2003a) suggested that the particle-size growth due to water absorption and coagulation with other aerosols or the existence of aspherically shaped particles, would help to reconcile the discrepancy between theoretical and model values for the scavenging efficiency of small particles.

Evaporation of rainwater is considered when calculating the wet deposition rate. When evaporation occurs, a fraction of the trace elements is released into the air. The fraction of the released trace elements is assumed to be proportional to the amount of evaporated rainwater.

\section{Results and discussion}

We performed a 25-year simulation (from October 1978 to the end of 2003) to obtain a climatological global dust distribution. The results of the first three months were discarded 
as representing a spin-up period. Results were stored as daily and monthly mean values, and then averaged to obtain climatological values. The model resolution of this simulation is T63 (about $1.8^{\circ} \times 1.8^{\circ}$ ) with 30 vertical layers. The horizontal wind components are assimilated with National Centers for Environmental Prediction - Department of Energy (NCEPDOE) Reanalysis 2 data to obtain a realistic atmospheric field.

\subsection{Global simulation}

\section{a. Emission and deposition}

Figure 2a depicts the annually and globally averaged global dust-emission flux, the dry and wet deposition fluxes, and the dust load for each size-bin; Table 3 shows those values for clay $(D \leq 2 \mu \mathrm{m})$ and silt $(D>2 \mu \mathrm{m})$. The annual mean global dust-emission flux over the size range $0.2 \leq D \leq 20 \mu \mathrm{m}$ is $2149 \mathrm{Tg} \mathrm{yr}^{-1}$ and varies from 1818 to $2339 \mathrm{Tg} \mathrm{yr}^{-1}$. Figure $2 \mathrm{a}$ demonstrates that the dust-emission flux has its peak around $7 \mu \mathrm{m}$. The emission flux of silt particles (1733 $\mathrm{Tg} \mathrm{yr}^{-1}$ ) is more than four times larger than that of clay particles $\left(416 \mathrm{Tg} \mathrm{yr}^{-1}\right)$, but the atmospheric load of silt particles $(8.0 \mathrm{Tg})$ is smaller than that of clay particles $(10.0 \mathrm{Tg})$. The relative importance of dry and wet deposition changes at about $3 \mu \mathrm{m}$, near the value at which clay and silt particles are distinguished. Dry deposition dominates for the silt particles due to the large gravitational settling velocity. In contrast, clay particles are mainly scavenged by wet deposition. This is consistent with some previous studies (Tegen and Fung 1994; Zender et al. 2003a), although not with the result of Ginoux et al. (2001). The atmospheric dust load peaks around 2 to $3 \mu \mathrm{m}$. The peak of the size distribution is consistent with that of measured size distributions, such as that by Duce (1995).

Figure $2 \mathrm{~b}$ illustrates the lifetime of each

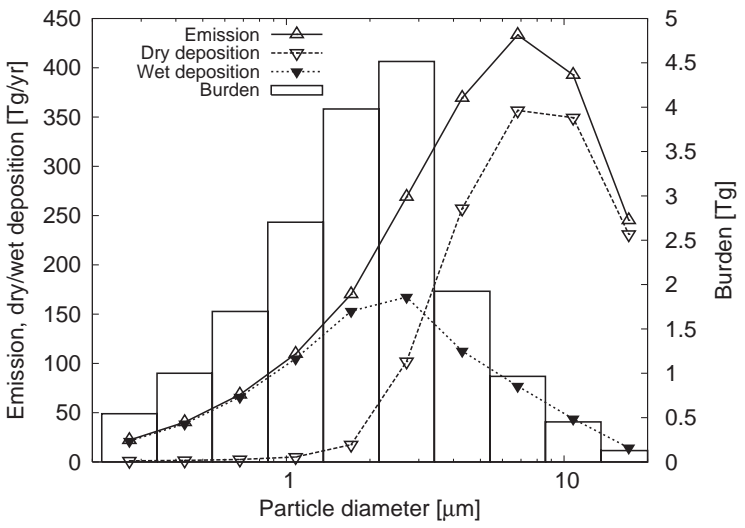

(a)

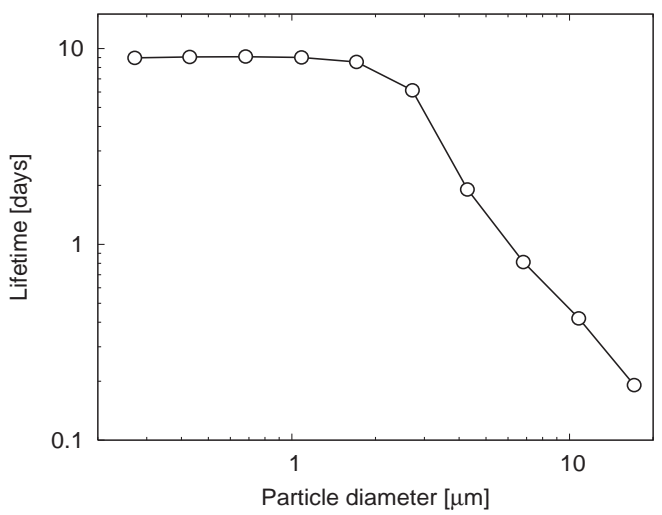

(b)

Fig. 2. Size dependence of (a) dustemission flux, dry and wet deposition flux, and atmospheric load; and (b) lifetime. Annual and global mean values of the size-bins are plotted.

transported size-bin. The calculated lifetime of all dust particles is 3.1 days, although this depends strongly on particle size. The lifetimes for the size-bins in the clay-size range are almost constant at about 9 days. The lifetime of silt particles $(D>2 \mu \mathrm{m})$ decreases almost

Table 3. Global and annual mass budget of simulated dust aerosol over 25 years (1979 to 2003), showing clay, silt, and total transported dust.

\begin{tabular}{lcccrc}
\hline Size-bin & $\begin{array}{c}\text { Source } \\
\left(\mathrm{Tg} \mathrm{yr}^{-1}\right)\end{array}$ & $\begin{array}{c}\text { Dry deposition } \\
\left(\mathrm{Tg} \mathrm{yr}^{-1}\right)\end{array}$ & $\begin{array}{c}\text { Wet deposition } \\
\left(\mathrm{Tg} \mathrm{yr}^{-1}\right)\end{array}$ & $\begin{array}{c}\text { Total load } \\
(\mathrm{Tg})\end{array}$ & $\begin{array}{c}\text { Lifetime } \\
(\text { days })\end{array}$ \\
\hline Clay $(D \leq 2 \mu \mathrm{m})$ & 416 & 28 & 388 & 10.0 & 8.8 \\
Silt $(D>2 \mu \mathrm{m})$ & 1733 & 1314 & 421 & 8.0 & 1.7 \\
\hline Total & 2149 & 1342 & 808 & 18.0 & 3.1 \\
\hline
\end{tabular}




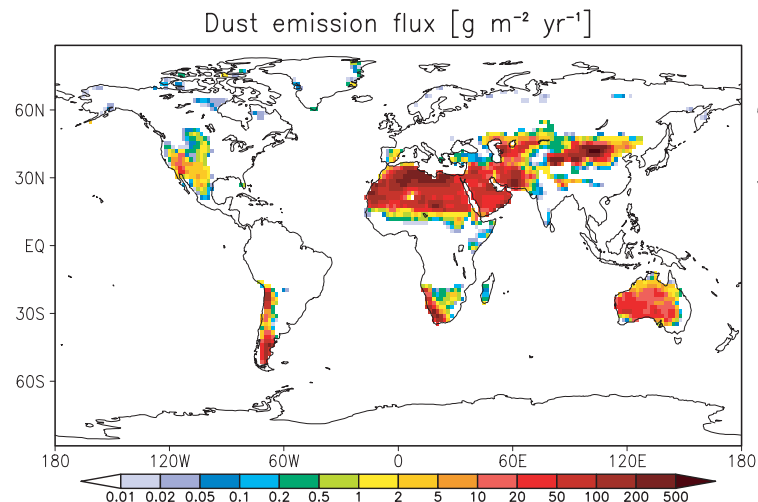

(a)

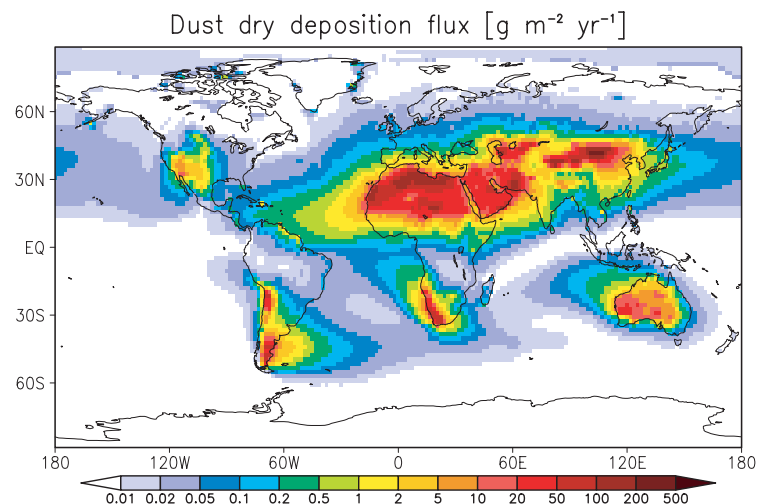

(c)

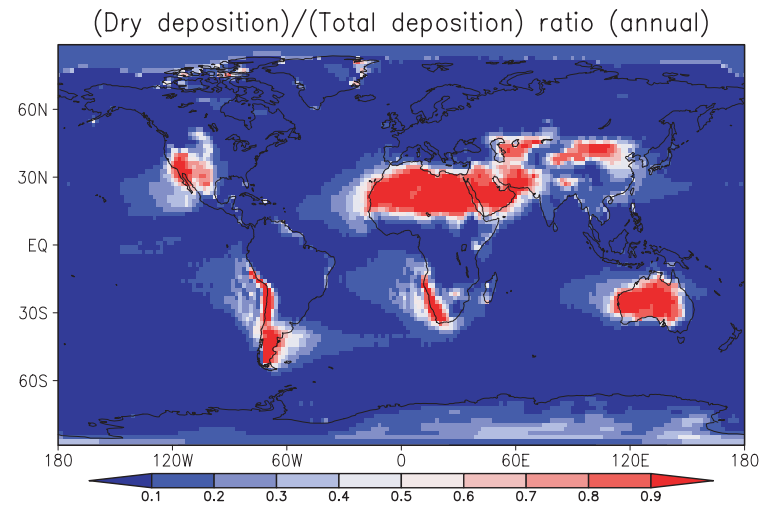

(e)

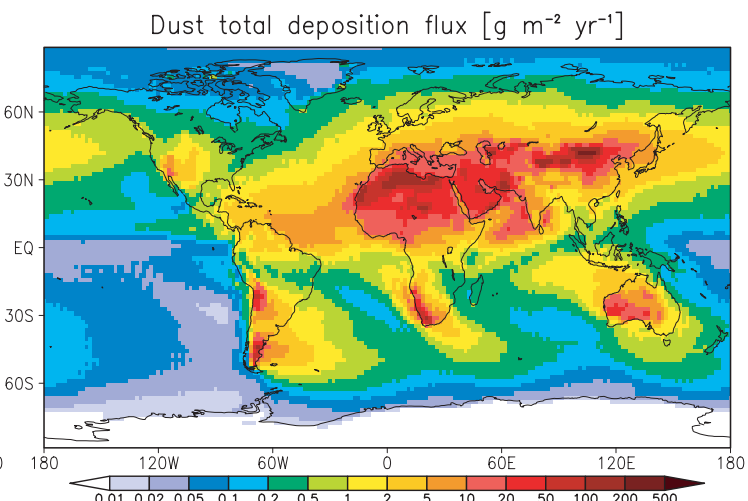

(b)

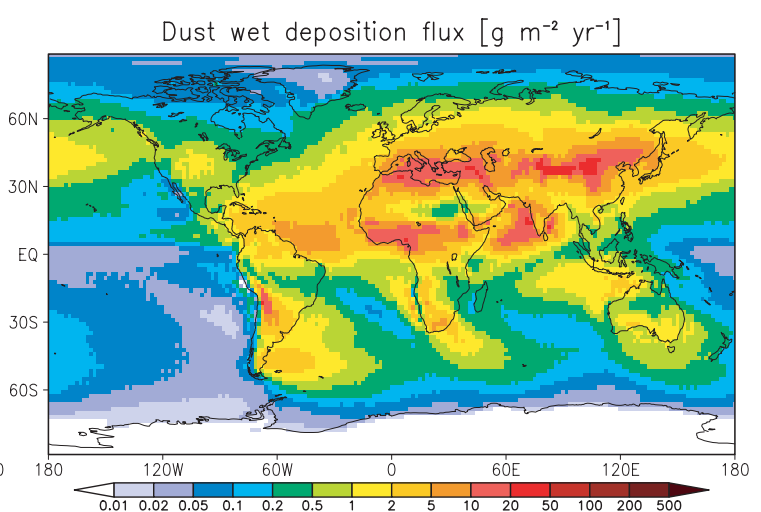

(d)

Fig. 3. Simulated annual mean dust source and sink fluxes. (a) emission, (b) total deposition, (c) dry deposition, (d) wet deposition, and (e) fractional ratio of dry deposition to total deposition. The units of (a)-(d) are $\mathrm{g} \mathrm{m}^{-2} \mathrm{yr}^{-1}$. In (e), red areas are dominated by dry deposition, and blue areas are dominated by wet deposition.

we increase the size-bin to a size larger than $20 \mu \mathrm{m}$, the total dust emission will increase but the dust load will not change much, leading to a shorter lifetime. The size distribution of dust emission is critically important for the discussion of a mass budget for atmospheric dust.

Figure 3a illustrates the global distribution of the simulated annual mean dust-emission 
flux. The major dust source regions correspond to bare desert and semi-desert regions. Figure $3 \mathrm{~b}$ depicts the distribution of annual mean total deposition flux, while Figs. 3c and 3d decompose this into dry and wet deposition fluxes. Figure 3e shows the fractional ratio of dry deposition flux to total deposition flux. High dry deposition flux occurs in the source regions because of the sedimentation of large particles. In contrast, high wet deposition flux occurs far from the dust source regions. Because wet deposition flux is associated not only with dust concentration but also with precipitation, high wet deposition flux occurs over the tropical Atlantic and Indian Oceans. Wet deposition accounts for $38 \%$ of the total global deposition, $82 \%$ over oceans, and $26 \%$ over land.

The dust-emission flux on a global scale and for nine major dust-emission regions is illustrated in Fig. 4. It is shown that global dust emission is maximized during the northern spring, when dust emissions from North Africa and eastern China reach their peaks. The figure demonstrates that North Africa is the largest contributor to global dust emission throughout the year, emitting about half of the annual mean global dust.

\section{b. Global column integrated dust distribution}

The annually and seasonally averaged simulated column dust amounts are presented in

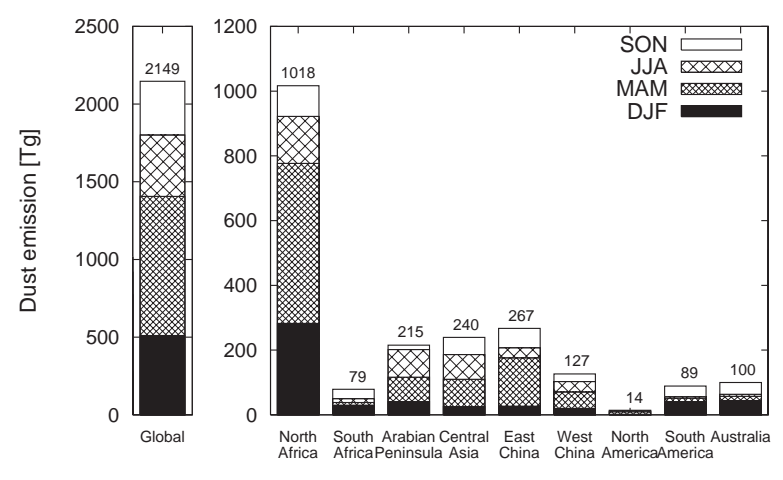

(a). Global Dust

(b). Dust source region

Fig. 4. (a) Global and (b) regional dustemission amounts (unit: Tg). Each bar is divided into seasonal averages for DJF, MAM, JJA, and SON. The annual average emission is given at the top of each bar.
Fig. 5. The peak values of column amounts are located over North Africa, the Arabian Peninsula, the Chinese deserts (i.e., the Taklimakan and the Gobi Deserts), Australia, South Africa, Chile (the Atacama Desert), and Patagonia. The highest dust load is located over North Africa. Our column amount patterns are quite similar to those from previous global dust model studies (Ginoux et al. 2001; Tegen et al. 2002; Lunt and Valdes 2002; Zender et al. 2003a; Miller et al. 2004). However, some differences can be seen in the following points: (1) the peaks over the East Asian region are seen in our model and in other model results, although our results show higher values than those of previous studies; (2) our results show a large peak over Chile and South Africa, whereas some models (Zender et al. 2003a; Tegen et al. 2002) do not; and (3) the maximum over Australia is located in the western area, although in some models and in the Total Ozone Mapping Spectrometer (TOMS) aerosol index (Prospero et al. 2002), the maximum is seen over Lake Eyre.

Figure 5 shows that the dust load is high from spring to summer. The Saharan and East Asian dust plumes peak during northern spring, as determined by satellite and surface observations. In JJA, the dust load from the Arabian Peninsula to the Indian Ocean becomes high, as can be seen in the satellite retrieval images of the TOMS aerosol index and Advanced Very High Resolution Radiometer (AVHRR) (Husar et al. 1997; Chin et al. 2002). The seasonal shift of the Saharan dust plume path with migration of the inter-tropical convergence zone, which is seen in satellite observations (Husar et al. 1997; Herman et al. 1997) and in other model studies (Tegen and Fung 1995; Takemura et al. 2000; Ginoux et al. 2001), is shown in the figures.

\section{c. Vertical distribution}

Figure 6 compares the simulated and observed vertical profiles of dust concentrations over Barbados during June and July. The observed profiles are taken from the vertical distributions of insoluble aerosol in Prospero and Carlson (1972). The simulated profile accurately reproduces the vertical extent and magnitude of the observed Saharan dust layer, which extends from 1.5 to $3.7 \mathrm{~km}$ altitude, 


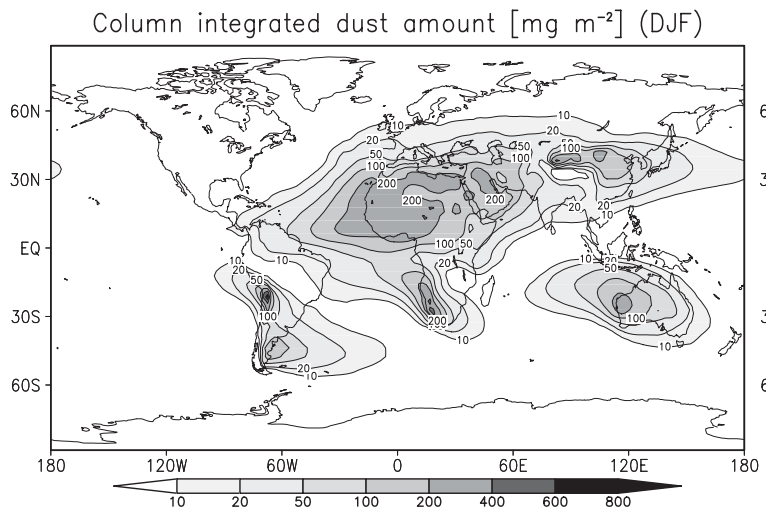

(a)

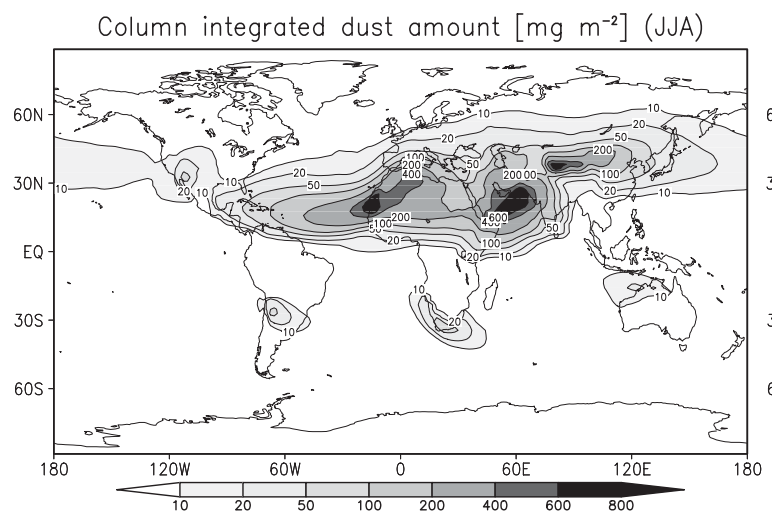

(c)

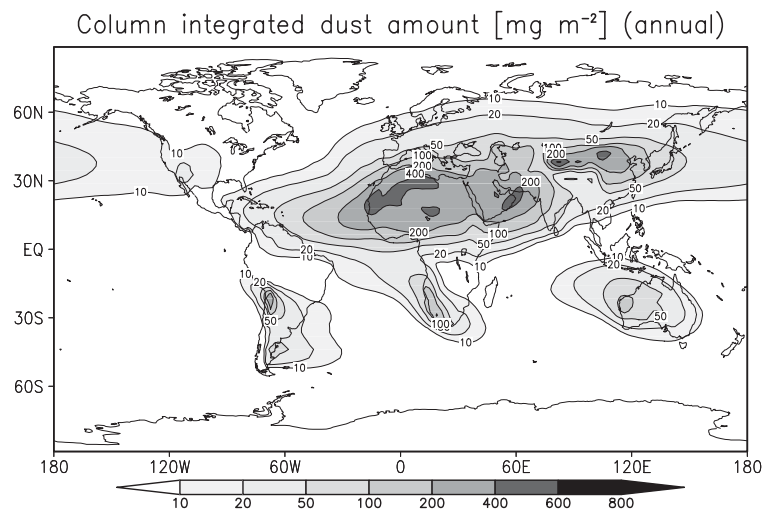

(e)

although the simulated concentration below $1.5 \mathrm{~km}$ is somewhat high, and the simulated concentration decreases gradually with height between 3 and $5 \mathrm{~km}$, whereas the observed data shows a sharper decrease.

Seasonal and annual averaged zonal mean dust concentrations are shown in Fig. 7. In general, dust concentration decreases rapidly

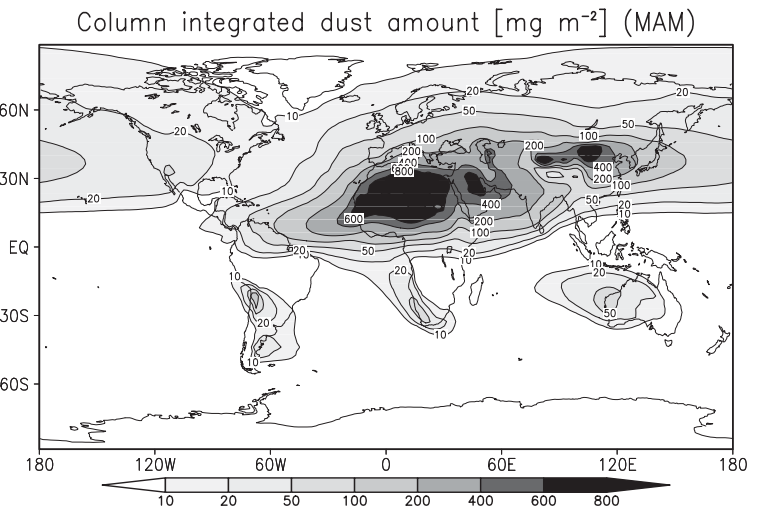

(b)

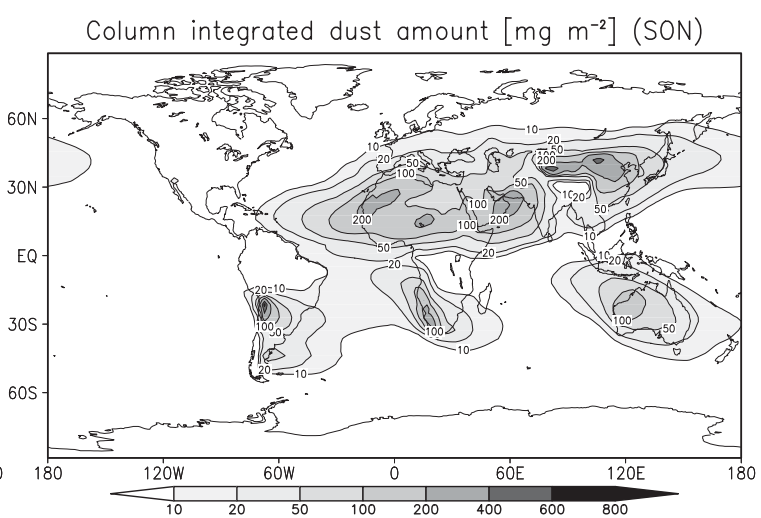

(d)
Fig. 5. Column integrated dust load for (a) December to February (DJF), (b) March to May (MAM), (c) June to August (JJA), (d) September to November (SON), and (e) annual mean. The unit is $\mathrm{mg} \mathrm{m}^{-2}$.

with height. In the free troposphere, zonal mean dust concentrations are in the range of 0 to $10 \mu \mathrm{g} \mathrm{m}^{-3}$. The figures show maxima throughout the year in the subtropical regions, where the Earth's major deserts are located.

During the northern spring, dust concentrations become high around $40^{\circ} \mathrm{N}$ and dust is transported to the upper troposphere, probably 


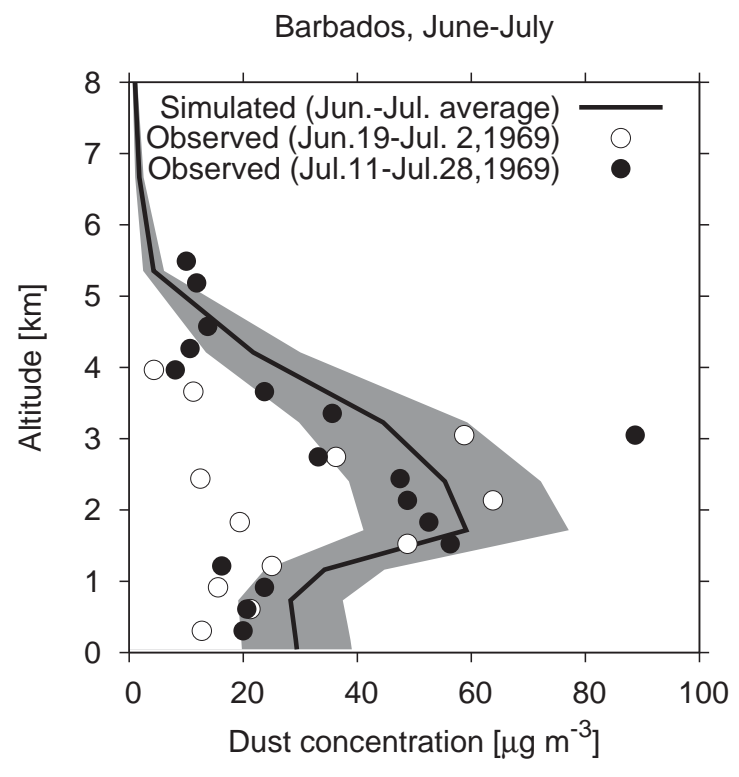

Fig. 6. Simulated and observed vertical profiles of dust concentration over Barbados during June and July. One standard deviation for the simulated values in the 25-year simulation is shown by shadings. The observed profiles were taken from the vertical distributions of insoluble aerosol in Prospero and Carlson (1972). The observed data in this figure were corrected for a filter efficiency of $80 \%$.

because of the increase in dust emissions from East Asia. The contour line of $1 \mu \mathrm{g} \mathrm{m}^{-3}$ reaches over $300 \mathrm{hPa}$. The figure shows a strong northward meridional transport to high latitudes at about 400 to $500 \mathrm{hPa}$. Previous studies by Ginoux et al. (2001) and Tegen and Fung (1994) also show a meridional dust transport, but at different altitudes; Ginoux et al. (2001) shows it at about $800 \mathrm{hPa}$, and Tegen and Fung (1994), at about $100 \mathrm{hPa}$. During the northern summer, dust at around $20^{\circ} \mathrm{N}$ is significant due to the active vertical mixing in the boundary layer over the Saharan and Arabian regions.

Dust at high altitude may have a climatic impact through interactions with clouds. First, dust has positive radiative forcing over a high albedo surface due to its absorptive nature. Second, dust has an indirect radiative impact through ice clouds (Sassen 2002) because it is known to function as nuclei for condensation of ice (Isono et al. 1959). Recent studies of lidar observations have found that ice clouds can form at higher temperatures when they coexist with dust plumes (Sassen 2002; Sassen et al. 2003; DeMott et al. 2003; Sakai et al. 2003). There is a possibility that dust has an indirect effect on global climate by changing the radiative properties of ice clouds. Since this indirect effect of dust as ice nuclei has not been evaluated, it remains as a subject of future research of global climate change.

\subsection{Comparison of the dust budget with other global dust model studies}

Table 4 summarizes the annual mean global dust budget in this study and in other recent studies of global dust models (Mahowald et al. 1999; Takemura et al. 2000; Ginoux et al. 2001; Chin et al. 2002; Tegen et al. 2002; Werner et al. 2002; Zender et al. 2003a; Luo et al. 2003; Miller et al. 2004). Current estimates of global dust emissions range from 1019 to

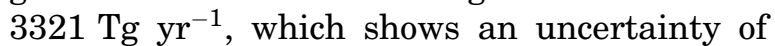
about a factor of 3 . If the studies are restricted to those published after the year 2001, the range is reduced to 1019 to $2150 \mathrm{Tg} \mathrm{yr}^{-1}$. Simultaneous estimates of the atmospheric dust load range from 8 to $36 \mathrm{Tg}$, which represents an uncertainty factor of 4 . Table 4 shows that the estimated dust emission amount does not necessarily correspond to the dust load. The global total dust emission and load in this study are within the ranges of recent estimates, but our dust-emission flux is the largest among the studies published after 2001.

There are large discrepancies among the studies concerning the lifetime of dust particles (1.5 to 7.4 days) and the ratio of dry deposition versus wet deposition (1.03 to 8.10) as shown in Table 4. One reason for these discrepancies may be the differences in size distribution of dust emission, which we have discussed previously. Another reason may be the treatment of wet deposition. As we have indicated, claysized particles are scavenged almost entirely by wet deposition processes. The estimated lifetime of clay-sized particles under MASINGAR is 9 days, which is consistent with the result of Miller et al. (2004), but shorter than that of Ginoux et al. (2001) (14 days) and Zender et al. (2003a) (17 days). Uncertainties in the treatment of wet deposition will lead to uncertainties in evaluating the radiative forcing 


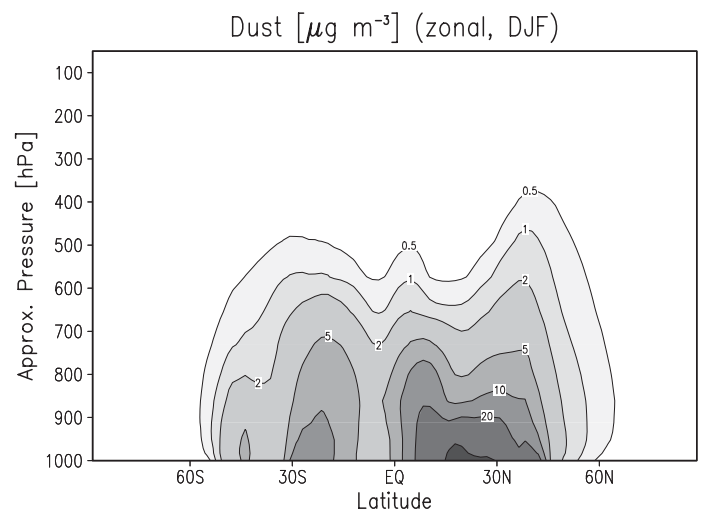

(a)

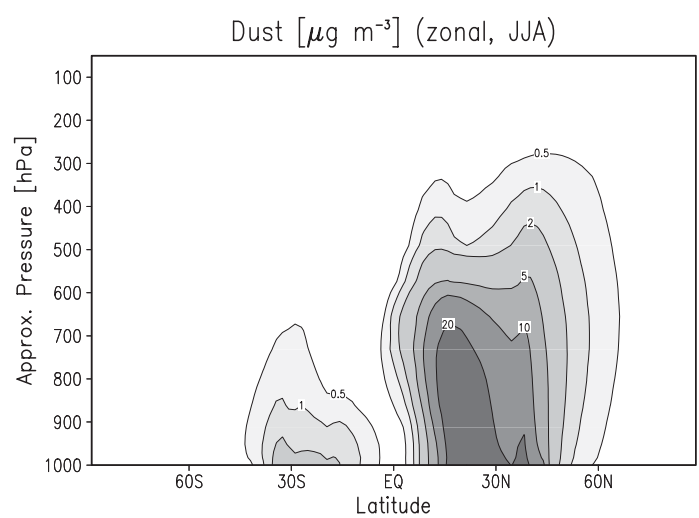

(c)

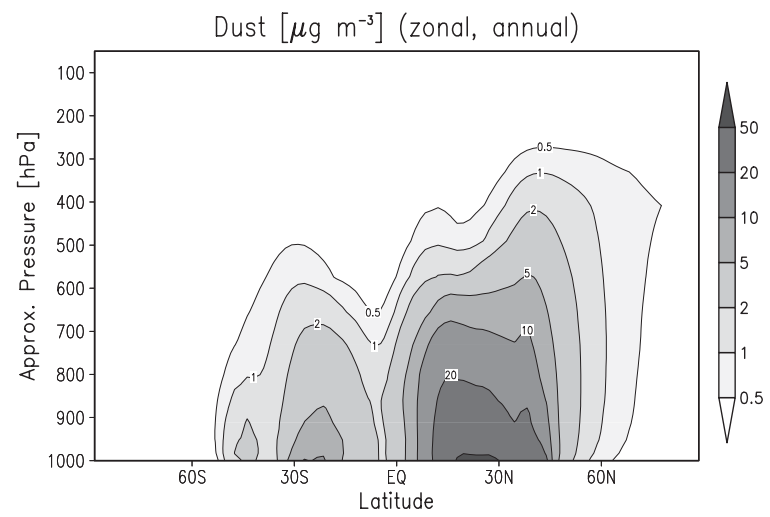

(e)

of dust because clay-sized particles are efficient in the scattering of solar radiation.

Table 5 compares the regional annual mean dust flux in this study and in other recent global dust model studies (Werner et al. 2002; Zender et al. 2003a; Ginoux et al. 2004; Miller et al. 2004). While all studies agree that North Africa is the most important source region, re-

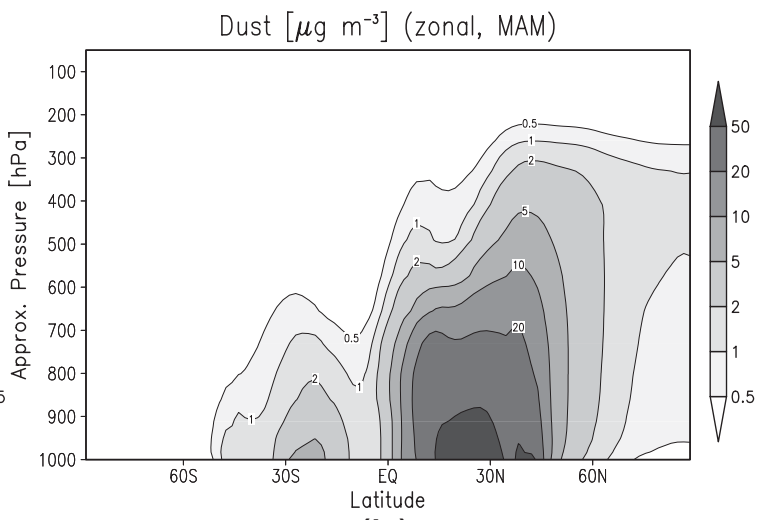

(b)

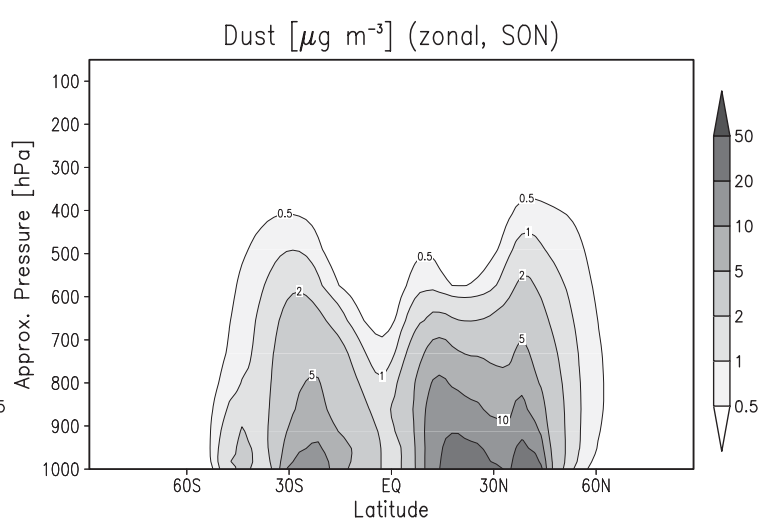

(d)
Fig. 7. Zonal mean dust concentration for (a) DJF, (b) MAM, (c) JJA, (d) SON, and (e) annual mean. The unit is $\mu \mathrm{g} \mathrm{m}^{-3}$.

sults on the relative importance of other regions are quite different. Based on our model calculation, $39 \%$ of global dust is emitted from Asia (Arabia, Central, and East Asia) while other models estimate it to be less than $28 \%$. As for North America, this study and Zender et al. (2003a) calculate very small $(0.6 \%$ and $0.5 \%)$ amounts of dust, whereas Miller et al. (2004) 
Table 4. Comparison of global and annual mean dust budget between this study and other recent studies of global dust models.

\begin{tabular}{|c|c|c|c|c|c|c|c|c|}
\hline & 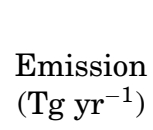 & $\begin{array}{c}\text { Dry } \\
\text { deposition } \\
\left(\mathrm{Tg} \mathrm{yr}^{-1}\right)\end{array}$ & $\begin{array}{c}\text { Wet } \\
\text { deposition } \\
\left(\mathrm{Tg} \mathrm{yr}^{-1}\right)\end{array}$ & $\begin{array}{l}\text { Dry/ } \\
\text { Wet } \\
\text { ratio }\end{array}$ & $\begin{array}{c}\text { Load } \\
(\mathrm{Tg})\end{array}$ & $\begin{array}{l}\text { Lifetime } \\
\text { (days) }\end{array}$ & $\begin{array}{c}\text { Diameter } \\
\text { range }(\mu \mathrm{m})\end{array}$ & $\begin{array}{c}\text { Number } \\
\text { of bins }\end{array}$ \\
\hline This study & 2149 & 1342 & 808 & 1.66 & 18.0 & 3.1 & $0.2-20$ & 10 \\
\hline $\begin{array}{l}\text { Mahowald } \\
\text { et al. (1999) }\end{array}$ & 3000 & $1840 *$ & $1170^{*}$ & 1.57 & $35^{*}$ & 4.3 & \multicolumn{2}{|c|}{$\begin{array}{l}\text { mass median } 2.5 \\
1 \text { bin }\end{array}$} \\
\hline $\begin{array}{l}\text { Takemura } \\
\text { et al. }(2000)\end{array}$ & 3321 & 2670 & 651 & 4.10 & 13.8 & 1.5 & $0.2-20$ & 10 \\
\hline $\begin{array}{l}\text { Ginoux } \\
\text { et al. (2001) }\end{array}$ & 1814 & 1606 & 235 & 6.83 & 35.9 & 7.2 & $0.2-12$ & 7 \\
\hline $\begin{array}{l}\text { Chin } \\
\text { et al. (2002) }\end{array}$ & 1650 & 1483 & 183 & 8.10 & 28.7 & 6.3 & $0.2-12$ & 7 \\
\hline $\begin{array}{l}\text { Tegen } \\
\quad \text { et al. (2002) }\end{array}$ & 1100 & 724 & 374 & 1.94 & 22.2 & 7.4 & $0.2-440$ & 7 \\
\hline $\begin{array}{l}\text { Werner } \\
\text { et al. (2002) }\end{array}$ & 1060 & 811 & 244 & 3.32 & 8 & 2.8 & $0.2-438$ & 7 \\
\hline $\begin{array}{l}\text { Zender } \\
\quad \text { et al. (2003a) }\end{array}$ & 1490 & 866 & 607 & 1.43 & 17.4 & 4.3 & $0.1-10$ & 4 \\
\hline $\begin{array}{l}\text { Luo et al. } \\
\quad(2003)\end{array}$ & 1654 & 823 & 798 & 1.03 & 23 & 5.1 & $0.1-10$ & 4 \\
\hline $\begin{array}{l}\text { Miller et al. } \\
\quad(2004)\end{array}$ & 1019 & $595 *$ & $414^{*}$ & 1.44 & 14.6 & 5.2 & $0.2-16$ & 4 \\
\hline
\end{tabular}

*: Calculated from presented lifetime.

Table 5. Comparison of regional annual mean dust flux between this study and other recent

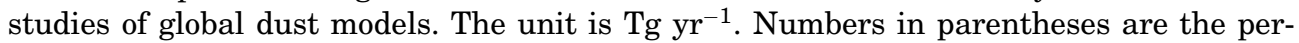
centages for the annual mean global emission flux.

\begin{tabular}{|c|c|c|c|c|c|c|c|c|}
\hline & \multicolumn{2}{|c|}{ Africa } & \multicolumn{3}{|c|}{ Asia } & \multicolumn{2}{|c|}{ America } & \multirow[b]{2}{*}{ Australia } \\
\hline & North & South & Arabia & Central & East & North & South & \\
\hline This study & $\begin{array}{c}1018 \\
(47 \%)\end{array}$ & $\begin{array}{c}79 \\
(3.7 \%)\end{array}$ & $\begin{array}{c}215 \\
(10 \%)\end{array}$ & $\begin{array}{c}240 \\
(11 \%)\end{array}$ & $\begin{array}{c}394 \\
(18 \%)\end{array}$ & $\begin{array}{c}14 \\
(0.6 \%)\end{array}$ & $\begin{array}{c}89 \\
(4.1 \%)\end{array}$ & $\begin{array}{c}100 \\
(4.7 \%)\end{array}$ \\
\hline Werner et al. (2002) & $\begin{array}{c}693 \\
(65 \%)\end{array}$ & & $\begin{array}{c}101 \\
(9.5 \%)\end{array}$ & \multicolumn{2}{|c|}{$\begin{array}{c}96 \\
(9.0 \%)\end{array}$} & & & $\begin{array}{c}52 \\
(4.9 \%)\end{array}$ \\
\hline Zender et al. (2003a) & \multicolumn{2}{|c|}{$\begin{array}{c}980 \\
(66 \%)\end{array}$} & \multicolumn{3}{|c|}{$\begin{array}{c}415 \\
(28 \%)\end{array}$} & $\begin{array}{c}8 \\
(0.5 \%)\end{array}$ & $\begin{array}{c}35 \\
(2.3 \%)\end{array}$ & $\begin{array}{c}37 \\
(2.5 \%)\end{array}$ \\
\hline Ginoux et al. (2004) & \multicolumn{2}{|c|}{$\begin{array}{c}1430 \\
(69 \%)\end{array}$} & \multicolumn{3}{|c|}{$\begin{array}{c}496 \\
(24 \%)\end{array}$} & $\begin{array}{c}9 \\
(0.4 \%)\end{array}$ & $\begin{array}{c}55 \\
(2.6 \%)\end{array}$ & $\begin{array}{c}61 \\
(2.9 \%)\end{array}$ \\
\hline Miller et al. (2004) & $\begin{array}{c}517 \\
(51 \%)\end{array}$ & & $\begin{array}{c}43 \\
(4.2 \%)\end{array}$ & $\begin{array}{c}163 \\
(16 \%)\end{array}$ & $\begin{array}{c}50 \\
(4.9 \%)\end{array}$ & $\begin{array}{c}53 \\
(5.2 \%)\end{array}$ & & $\begin{array}{c}148 \\
(15 \%)\end{array}$ \\
\hline
\end{tabular}

calculate a relatively large amount (5.2\%), which is larger than the calculated amount from the Arabian Peninsula or East Asia. Similar differences are also found in the case of Australian dust. However, there are no observational data available to confirm the relative strength of each source region.

\subsection{Station-based comparisons with} observations

a. Comparison with the University of Miami aerosol network data

We compared our monthly mean dust concentration with that of the University of Miami aerosol network data (J. Prospero and 


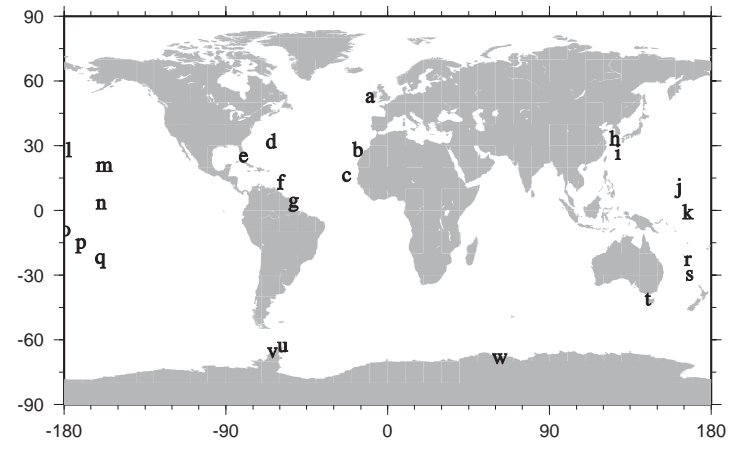

Fig. 8. Locations of the University of Miami aerosol network. Site characters are (a) Mace Head $\left(53.3^{\circ} \mathrm{N}, 9.9^{\circ} \mathrm{W}\right)$, (b) Izaña $\left(28.3^{\circ} \mathrm{N}, 16.5^{\circ} \mathrm{W}\right)$, (c) Sal Island $\left(16.8^{\circ} \mathrm{N}, 22.9^{\circ} \mathrm{W}\right),(\mathrm{d})$ Bermuda $\left(32.3^{\circ} \mathrm{N}\right.$, $\left.64.9^{\circ} \mathrm{W}\right)$, (e) Miami $\left(25.8^{\circ} \mathrm{N}, 80.3^{\circ} \mathrm{W}\right)$, (f) Barbados $\left(13.2^{\circ} \mathrm{N}, 59.4^{\circ} \mathrm{W}\right),(\mathrm{g})$ Cayenne $\left(4.9^{\circ} \mathrm{N}, \quad 52.3^{\circ} \mathrm{W}\right), \quad$ (h) Jeju $\left(33.5^{\circ} \mathrm{N}\right.$, $\left.126.5^{\circ} \mathrm{E}\right)$, (i) Hedo $\left(26.9^{\circ} \mathrm{N}, 128.3^{\circ} \mathrm{E}\right),(\mathrm{j})$ Enewetak Atoll $\left(11.3^{\circ} \mathrm{N}, 162.3^{\circ} \mathrm{E}\right),(\mathrm{k})$ Nauru $\left(0.5^{\circ} \mathrm{S}, 166.9^{\circ} \mathrm{E}\right)$, (l) Midway Island $\left(28.2^{\circ} \mathrm{N}, 177.4^{\circ} \mathrm{W}\right),(\mathrm{m})$ Oahu $\left(21.3^{\circ} \mathrm{N}, 157.7^{\circ} \mathrm{W}\right),(\mathrm{n})$ Fanning Island $\left(3.9^{\circ} \mathrm{N}, 159.3^{\circ} \mathrm{W}\right)$, (o) Funafuti $\left(8.5^{\circ} \mathrm{S}\right.$, $\left.179.2^{\circ} \mathrm{W}\right),(\mathrm{p})$ American Samoa $\left(14.3^{\circ} \mathrm{S}\right.$, $\left.170.6^{\circ} \mathrm{W}\right)$, (q) Rarotonga $\left(21.3^{\circ} \mathrm{S}\right.$, $\left.159.8^{\circ} \mathrm{W}\right)$, (r) New Caledonia $\left(22.2^{\circ} \mathrm{S}\right.$, $\left.167.0^{\circ} \mathrm{E}\right)$, (s) Norfolk Island $\left(29.1^{\circ} \mathrm{S}\right.$, $\left.168.0^{\circ} \mathrm{E}\right)$, (t) Cape Grim $\left(40.7^{\circ} \mathrm{S}\right.$, $\left.144.7^{\circ} \mathrm{E}\right), \quad(\mathrm{u})$ King George Island $\left(62.2^{\circ} \mathrm{S}, 58.3^{\circ} \mathrm{W}\right)$, (v) Palmer Station $\left(64.8^{\circ} \mathrm{S}, 64.1^{\circ} \mathrm{W}\right)$, and (w) Mawson $\left(67.6^{\circ} \mathrm{S}, 62.5^{\circ} \mathrm{E}\right)$.

D. Savoie, personal communication). The locations of the sites with dust concentration records in the dataset are indicated in Fig. 8. The dataset consists of monthly records of surface dust concentration measurements, taken mainly at remote locations. Earlier global dust model studies have also been evaluated in comparison with the observational data from the University of Miami network (Tegen and Fung 1994; Ginoux et al. 2001; Tegen et al. 2002; Luo et al. 2003; Zender et al. 2003a).

Figure 9 compares the observed and simulated monthly mean surface dust concentrations at the sites of the University of Miami aerosol network. In general, seasonal variations in dust concentrations at stations in the northern hemisphere are simulated within the range of their variability. Two stations near the East Asian dust source regions (h, i) show especially good correlations, with a large peak in spring. Good agreement between observed and simulated dust concentrations is found at the stations near and downwind of the Saharan dust source (b, c, d, e, f, g), although the value for dust at Cayenne (g) from May to September seems too low. At stations in the remote North Pacific (j, k, l, m, n), dust concentrations exhibit a maximum in northern spring in both observation and simulation, although the simulation overestimates the peaks by up to a factor of 2 . Dust concentrations at several stations in the southern hemisphere (o, p, s, t), and especially in Antarctica (u, v, w) are underestimated, probably due to an underestimation of the dust from Australia and Patagonia.

Figure 10 presents a scatter diagram comparing the simulated climatological mean dust concentrations with observations made at the sites of the University of Miami aerosol network. Both the observed and the simulated dust concentrations span three orders of magnitude. At most of the stations, the model shows broad agreement with the observations within a factor of 2 . However, the model underestimates the dust concentrations at stations in the Antarctic region ( $\mathrm{w}, \mathrm{n}, \mathrm{v})$, as shown in Fig. 9.

\section{b. Comparison with DIRTMAP data}

Figure 11 compares the observed and simulated values for the annually averaged deposition flux in the DIRTMAP dataset (Mahowald et al. 1999). The figure shows that the model successfully simulates the observed deposition flux ranging over 5 orders of magnitude. At most stations, simulated dust depositions are generally in good agreement within a factor of 3 . However, the model tends to underestimate the deposition flux at some sites in the northern hemisphere.

It seems somewhat inconsistent that the simulated dust depositions agree at the sites in Antarctica, while surface dust concentrations are underestimated compared with observed data from the University of Miami aerosol network. This is probably due to the fact that the dust deposition flux is associated not only with the surface concentration but also with dust at a higher layer and precipitation flux. It is 

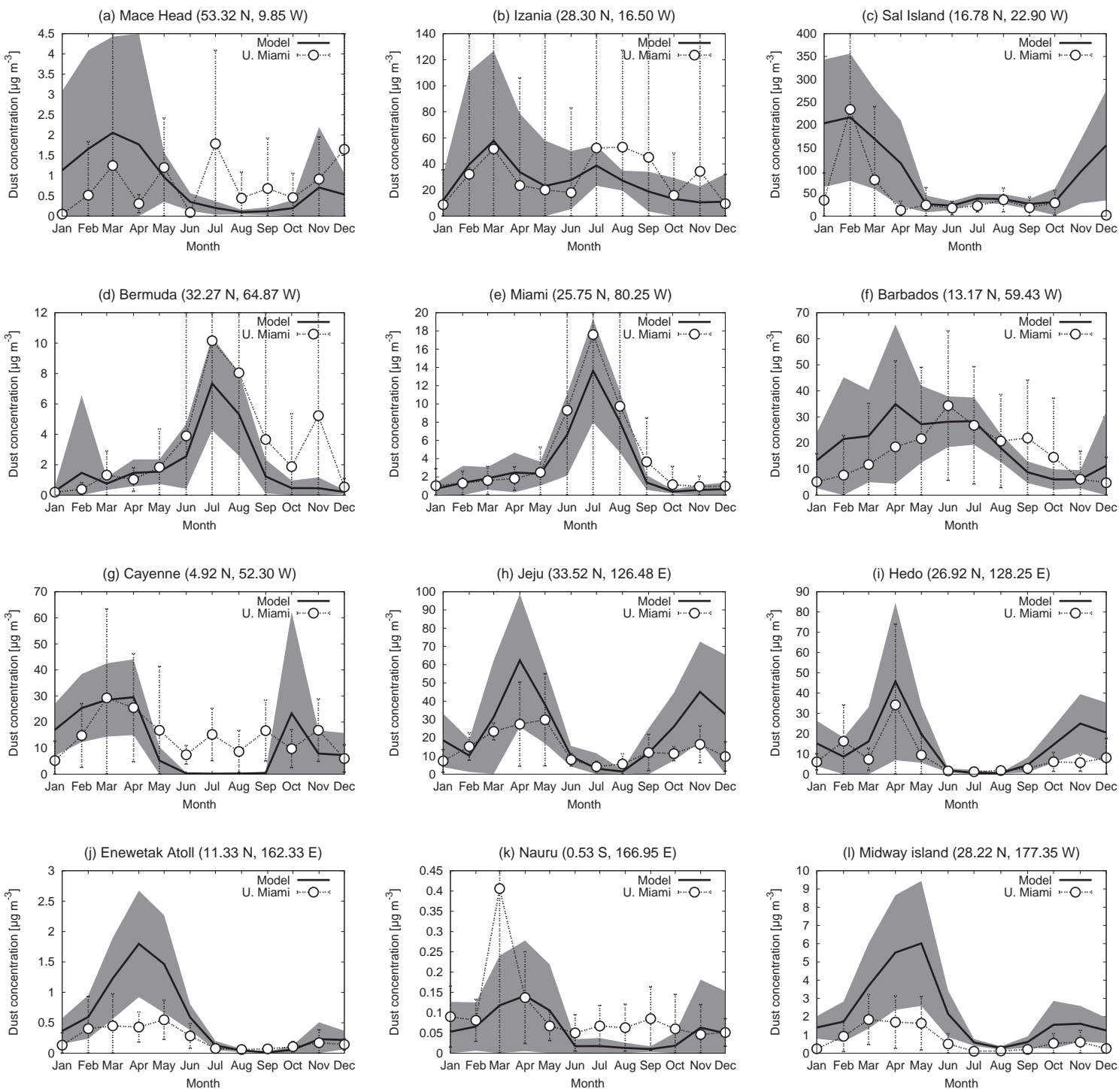

Fig. 9. Comparison of the observed (circles with dashes) and simulated (solid lines) monthly mean surface dust concentration at the sites of the University of Miami aerosol network (unit: $\mu \mathrm{g} \mathrm{m}^{-3}$ ). One standard deviation is shown by shading for simulated values, and by whiskers for observed values.

possible that simulated dust is not sufficiently mixed downward from higher layers. Another cause of the inconsistency could be the difference in time scales between the DIRTMAP deposition data and the University of Miami aerosol network concentration data. While deposition data taken from ice cores and marine sediments represent data covering a long period, the concentration data represent current meteorological conditions.

\subsection{Improvements to the model}

The present model still has many limitations and shortcomings. The model represents the dust aerosol with 10 size-bins, but interactions between size-bins, e.g., particle growth by aggregation, are not treated. The dust-emission model is based on the saltation-bombardment theory, but some potentially important properties are still missing, such as salt and organic material concentrations in the soil, surface 

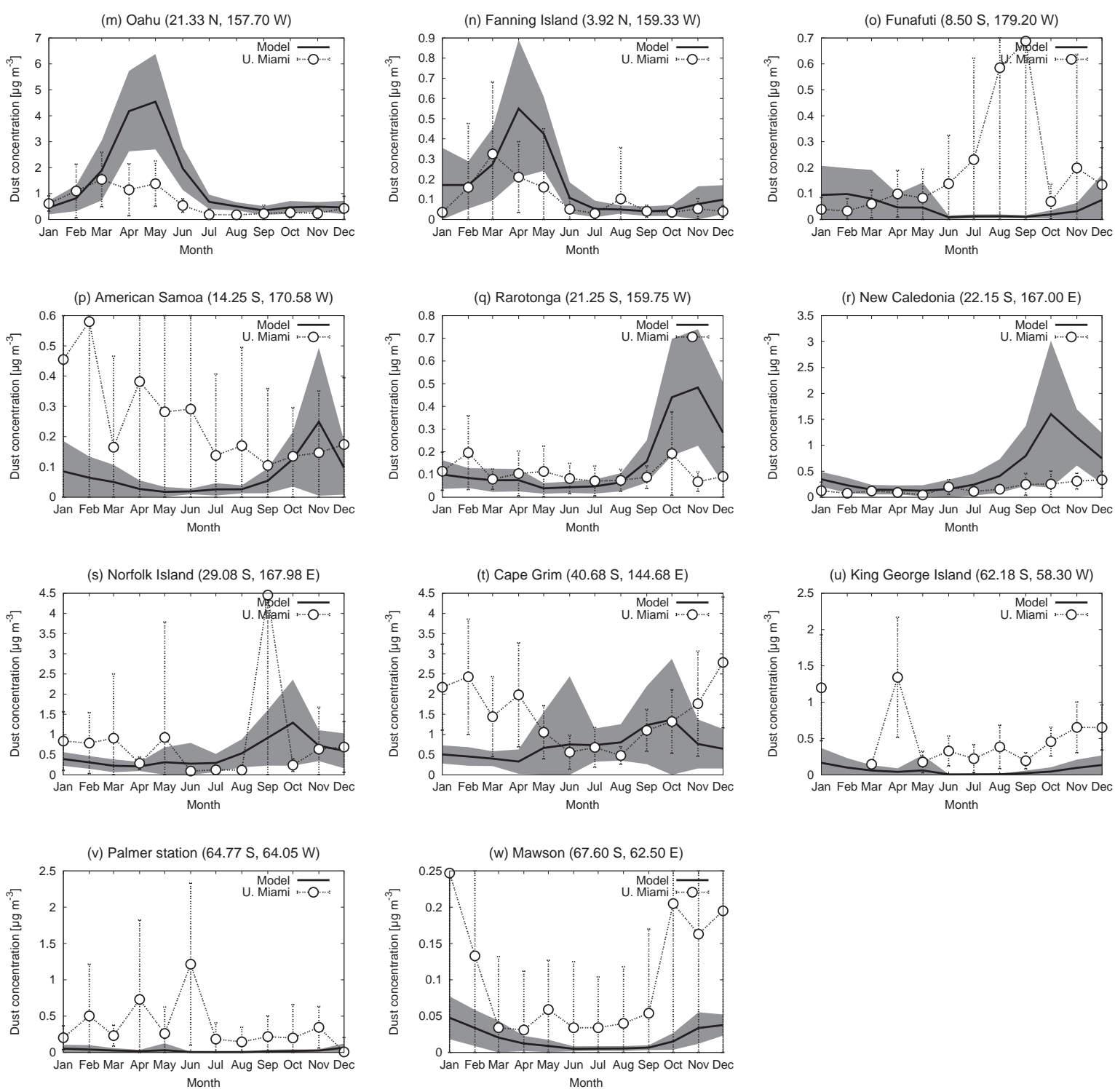

Month

Fig. 9. (continued)

crusting, binding by plant roots, geographical differences in smooth roughness length $\left(z_{0 s}\right)$, and the effect of surface sloping caused by dunes. The effects of these proprieties should be examined when quantitative data become available.

Comparison with the University of Miami aerosol network shows that dust sources in the southern hemisphere are underestimated. Some recent global models have introduced "preferential dust sources," based on topographical, geomorphic, or hydrological condi- tions (Ginoux et al. 2001; Tegen et al. 2002; Zender et al. 2003b). This study does not explicitly include these effects. Introduction of these effects may lead to better agreement with satellite retrievals.

One of the future tasks for this model is to update the land-surface databases, such as those for vegetation cover and land use. One advantage of this model is that the land-surface databases are consistent with the AGCM. However, there are two problems: first, they have coarse temporal and spatial resolution, which 


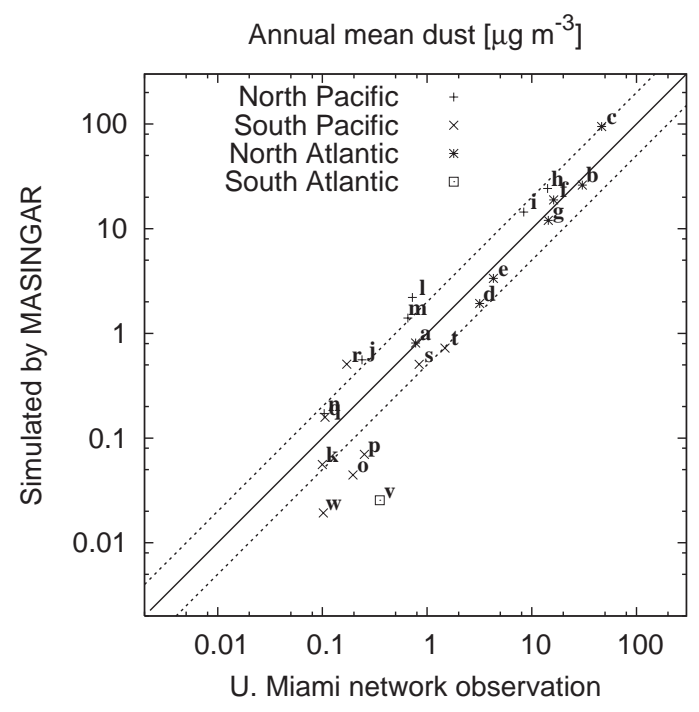

Fig. 10. Scatter diagram of the observed and simulated annual mean dust concentration at the sites of the University of Miami aerosol network (unit: $\mu \mathrm{g} \mathrm{m}^{-3}$ ). The solid diagonal line is the locus of perfect results, and the dashed diagonal lines indicate a factor-of-2 disparity. leads to an insufficient representation of vegetation growth, and second, the databases are somewhat old and cannot be used to evaluate the effect of desertification in recent years. We are considering using more up-to-date databases for vegetation cover including satelliteretrieved information (such as the Normalized Difference Vegetation Index) in a future version of the model.

Because we built the model based only on natural erosion under current climatic conditions, we did not differentiate between natural and anthropogenic dust sources. In order to evaluate the climatic impact of anthropogenic activities, we would need to identify and evaluate the main anthropogenic dust sources. We hope to include anthropogenic dust sources explicitly in a future version of this model.

\section{Conclusion}

We have developed a second-generation dust module incorporated into an on-line global dust transport model, MASINGAR. The module explicitly treats the size distribution of airborne

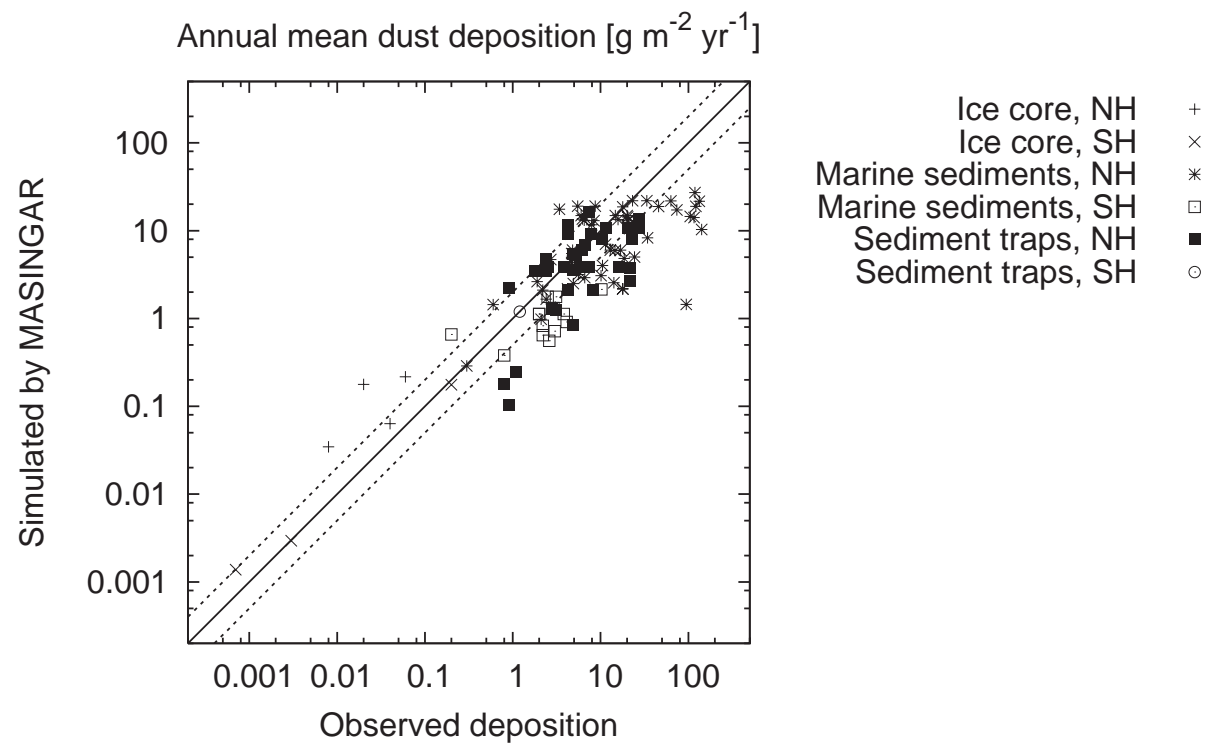

Fig. 11. Scatter diagram of the observed and simulated annual mean dust deposition flux (unit: $\mathrm{g} \mathrm{m}^{-2} \mathrm{yr}^{-1}$ ). The solid diagonal line is the locus of perfect results, and the dashed diagonal lines indicate a factor-of-3 disparity. The labels "Ice core," "Marine sediments," and "Sediment traps" represent the sampling methods used. "NH" and "SH" indicate whether the sampling location is in the northern hemisphere or the southern hemisphere. 
dust particles, of sizes from 0.2 to $20 \mu \mathrm{m}$, by dividing them into 10 independent size-bins. The dust-emission process is derived from the energy-based dust-emission model of Shao et al. (1996). This enables the module to predict the size distribution of a dust-emission flux based on the geographic variations in soil texture.

We performed a 25-year simulation of global dust distribution, covering 1979 to 2003 , and estimated the annual mean global total dust budget in the size range of 0.2 to $20 \mu \mathrm{m}$ as follows: the dust-emission flux is 2149 (17682340) $\mathrm{Tg} \mathrm{yr}^{-1}$, the atmospheric load is 18.0 (15.6-20.4) Tg, and the lifetime is 3.1 days. The simulated dust mass budgets are within the range of recent global model studies.

We have identified the mass budget of dust for each size-bin. The dust-emission flux peaks at around $7 \mu \mathrm{m}$. Silt particles are mainly removed from the atmosphere by dry deposition, while clay particles are removed by wet deposition. It is shown that the treatment of size distribution is critically important for evaluating the mass budget of dust.

The simulated surface dust concentration and deposition fluxes were evaluated by comparing them with the available observational data. Both simulated surface concentrations and deposition fluxes are in broad agreement with the observed data, especially at stations near the East Asian source regions. However, the model underestimates the surface concentrations for stations located at high latitudes in the southern hemisphere.

Our global dust model has limitations, especially regarding the uncertainties of groundsurface properties. Nonetheless, the model has successfully reproduced many features of the observed global dust distribution. Our future objectives include an evaluation of anthropogenic dust sources, a sensitivity study of the soil texture, and an analysis of the impact of ground-surface properties (soil moisture, snow cover, and vegetation cover) on dust-emission flux.

\section{Acknowledgments}

We would like to express our thanks to Prof. Joseph M. Prospero and Prof. Dennis L. Savoie for providing us with the University of Miami aerosol network data, and the Climate Re- search Department of the Meteorological Research Institute for the development of the MRI/JMA 98 AGCM. We would also like to thank Drs. Masao Mikami, Yasunori Kurosaki, and Naoko Seino of MRI for many fruitful discussions and Dr. Koji Imai for managing the 25-year integration. This study was funded by the Cooperative System for Supporting Priority Research of the Japan Science and Technology Corporation, and was conducted as part of the Aeolian Dust Experiment on Climate Impact (ADEC) project sponsored by the Ministry of Education, Culture, Sports, Science and Technology of the Japanese Government.

\section{Appendix}

\section{A. Transport processes of MASINGAR}

Each of the trace constituents is governed by the continuity equation, which includes advective, convective, and diffusive transports, together with emissions, wet and dry depositions, and gas- and aqueous-phase chemical reactions. Given the volume mixing ratio of the $i$ th chemical component at a time step $n\left(\chi_{i}\left(t_{n}\right)\right)$, the continuity equation is solved by successively applying operators to $\chi_{i}\left(t_{n}\right)$ as follows

$$
\chi_{i}\left(t_{n+1}\right)=A \cdot D \cdot C \cdot T \cdot \chi_{i}\left(t_{n}\right),
$$

where $A, D, C$, and $T$ are operators associated with the advective transport, eddy diffusion, convective transport, and transformation due to emission, deposition, and chemical reactions, respectively.

\section{A.1. Advection}

The advective transport for trace species in the model is performed using a semiLagrangian advection scheme (Staniforth and Côté 1991), which permits the use of much larger time steps than the Eulerian advection scheme, without sacrificing numerical stability or accuracy. The semi-Lagrangian scheme is three-dimensional, i.e., it first searches the upstream point with both horizontal and vertical wind, and then derives the mixing ratio using a three-dimensional interpolation. The interpolation scheme first calculates the third-order interpolated value, and then corrects overshooting or undershooting in advective flux with the first-order interpolation for mass conservation and non-negative treatment. 


\section{A.2. Eddy diffusion}

The eddy diffusive transport produced by the turbulent mixing process is expressed as

$$
\left(\frac{\partial \chi_{i}}{\partial t}\right)_{\text {diffusion }}=\frac{\partial}{\partial z}\left(K_{z} \frac{\partial \chi_{i}}{\partial z}\right)
$$

where $K_{z}$ is the vertical eddy diffusion coefficient. The $K_{z}$ value for trace gases and aerosols is taken from that for water vapor in the AGCM, which is calculated using the level 2 turbulence closure scheme from Mellor and Yamada (1974).

\section{A.3. Convective transport}

The convective transport is calculated using a mass flux (updraft and downdraft caused by the moist convection) with the ArakawaSchubert moist convection scheme (Arakawa and Schubert 1974) incorporated into the model. The algorithm first calculates the mixing ratio inside the convective updraft by solving the mass conservation equations for mass flux and the mixing ratios of chemical tracers

$$
\frac{\partial M_{u}}{\partial z}=E-D
$$

and

$$
\frac{\partial\left(M_{u} \chi_{u}\right)}{\partial z}=E \chi_{e}-D \chi_{u}
$$

where $M, E$, and $D$ are the convective mass flux, turbulent entrainment, and turbulent detrainment, respectively. The subscripts " $u$ " and " $e$ " designate variables associated with the convective updraft and with the environment, respectively. The entrainment is parameterized as

$$
E=\varepsilon M_{u},
$$

where $\varepsilon$ is the entrainment rate. The tendency of the mixing ratio due to convective transport is then calculated as

$$
\left(\frac{\partial \chi}{\partial t}\right)_{\text {convection }}=\frac{1}{\rho_{a}} \frac{\partial}{\partial z}\left(M_{u} \chi_{u}-M_{u} \chi_{e}\right) .
$$

Equations (35) through (38) are integrated with smaller time steps than was used for the advective transport in order to evaluate rapid convective motions and to obtain a more accurate solution. In practice, the time step for the convective transport is currently set to about 5 minutes.

\section{B. Data assimilation scheme}

The dynamical variables are assimilated with a nudging scheme that adds the tendency at each time step using a form of Newtonian relaxation forcing,

$$
\left(\frac{\partial x}{\partial t}\right)_{\text {nudging }}=-\frac{x-x_{\text {analysis }}}{\tau},
$$

where $x$ is a dynamical variable, $x_{\text {analysis }}$ is the corresponding observed dynamical variable from an optimal analysis, and $\tau$ is the time scale of the relaxation. The tendency implied by Eq. (39) is applied only above $850 \mathrm{hPa}$ because the coarse vertical grid of the optimal analysis data might otherwise destroy the structure of the planetary boundary layer of the model. The default value for the nudging time scale $\tau$ is 24 hours, which was determined from a sensitivity study.

\section{References}

Andreae, M.O., 1996: Raising dust in the greenhouse. Nature, 380, 389-390.

Arakawa, A. and W.H. Schubert, 1974: Interaction of a cumulus ensemble with the large-scale environment, part I. J. Atmos. Sci., 31, 674-701.

Bagnold, R.A., 1941: The Physics of Blown Sand and Desert Dunes. Methuen \& Co. Ltd., London, 320pp.

Chin, M., P. Ginoux, S. Kinne, O. Torres, B.N. Holben, B.N. Duncan, R.V. Martin, J.A. Logan, A. Higurashi, and T. Nakajima, 2002: Tropospheric aerosol optical thickness from the GOCART model and comparisons with satellite and sun photometer measurements. J. Atmos. Sci., 59, 461-483.

DeFries, R.S. and J.R.G. Townshend, 1994: NDVIderived land cover classification at a global scale. Int. J. Remote Sensing, 15, 3567-3586.

DeMott, P.J., K. Sassen, M.R. Poellot, D. Baumgardner, D.C. Rogers, S.D. Brooks, A.J. Prenni, and S.M. Kreidenweis, 2003: African dust aerosols as atmospheric ice nuclei. Geophys. Res. Lett., 30(14), 1732, doi:10.1029/2003GL017410.

Dentener, F.J., G.R. Carmichael, Y. Zhang, J. Lelieveld, and P.J. Crutzen, 1996: Role of mineral dust aerosol as a reactive surface in the global troposphere. J. Geophys. Res., 101, 2286922889.

Duce, R.A., 1995: Sources, distributions, and fluxes of mineral aerosols and their relation to cli- 
mate. R.J. Charlson and J. Heintzenberg, Eds., Aerosol Forcing of Climate, John Wiley, Hoboken, N. J, 43-72.

Fécan, F., B. Marticorena, and G. Bergametti, 1999: Parameterization of the increase of the aeolian erosion threshold wind friction velocity due to soil moisture for arid and semi-arid areas. Annales Geophysicae, 17, 149-157.

Gillette, D., 1978: A wind tunnel simulation of the erosion of soil: Effect of soil texture, sandblasting, wind speed, and soil consolidation on dust production. Atmos. Environ., 12, 17351743.

— and R. Passi, 1988: Modeling dust emission caused by wind erosion. J. Geophys. Res., 93, 14,233-14,242.

Ginoux, P., 2003: Effects of nonsphericity on mineral dust modeling. J. Geophys. Res., 108(D2), 4052, doi:10.1029/2002JD002516.

, M. Chin, I. Tegen, J.M. Prospero, B. Holben, O. Dubovik, and S.-J. Lin, 2001: Sources and distributions of dust aerosols simulated with the GOCART model. J. Geophys. Res., 106, 20255-20273.

, J.M. Prospero, O. Torres, and M. Chin, 2004: Long-term simulation of global dust distribution with the GOCART model: correlation with North Atlantic Oscillation. Environ. Model. Software, 19, 113-128.

Giorgi, F. and W.L. Chameides, 1986: Rainout lifetimes of highly soluble aerosols and gases as inferred from simulations with a general circulation model. J. Geophys. Res., 91, 1436714376.

Greeley, R. and J.D. Iversen, 1985: Wind as a geological process, No. 4 in Cambridge Planetary Science Series, Cambridge University Press, New York, 348pp.

Herman, J.R., P.K. Bhartia, O. Torres, C. Hsu, C. Seftor, and E. Celarier, 1997: Global distribution of UV-absorbing aerosols from Nimbus 7/TOMS data. J. Geophys. Res., 102, 1691116922.

Husar, R.B., J.M. Prospero, and L.L. Stowe, 1997: Characterization of tropospheric aerosols over the oceans with the NOAA advanced very high resolution radiometer optical thickness operational product. J. Geophys. Res., 102, 1688916909.

Ishizuka, M., M. Mikami, Yamada, Y., Z.F.J., and W. Gao, 2005: An observational study of soil moisture effects on wind erosion at a gobi site in the Taklimakan Desert. J. Geophys. Res., doi:10.1029/2004JD004709, in press.

Isono, K., M. Komabayasi, and A. Ono, 1959: The nature and origin of ice nuclei in the atmosphere. J. Meteor. Soc. Japan, 37, 211-233.
Jacobson, M.Z., 1999: Fundamentals of Atmospheric Modeling, Cambridge University Press, Cambridge, United Kingdom, 656pp.

Kurosaki, Y. and M. Mikami, 2004: Effect of snow cover on threshold wind velocity of dust outbreak. Geophys. Res. Lett., 31, L03106, doi:10.1029/2003GL018632.

Liu, M. and D.L. Westphal, 2001: A study of the sensitivity of simulated mineral dust production to model resolution. J. Geophys. Res., 106, 18099-18112.

Lunt, D.J. and P.J. Valdes, 2002: The modern dust cycle: Comparison of model results with observations and study of sensitivities. $J$. Geophys. Res., 107(D23), 4669, doi:10.1029/ 2002JD002316.

Luo, C., N.M. Mahowald, and J. del Corral, 2003: Sensitivity study of meteorological parameters on mineral aerosol mobilization, transport, and distribution. J. Geophys. Res., 108(D15), 4447, doi:10.1029/2003JD003483.

Mahowald, N., K. Kohfeld, M. Hansson, Y. Balkanski, S.P. Harrison, I.C. Prentice, M. Schulz, and H. Rodhe, 1999: Dust sources and deposition during the last glacial maximum and current climate: A comparison of model results with paleodata from ice cores and marine sediments. J. Geophys. Res., 104, 15895-15916.

Marticorena, B. and G. Bergametti, 1995: Modeling the atmospheric dust cycle: 1 . design of a soilderived dust emission scheme. J. Geophys. Res., 100, 16415-16430.

Martin, J.H., 1991: Iron still comes from above. Nature, 353, 123.

Martin, J.H. and S.E. Fitzwater, 1988: Irondeficiency limits phytoplankton growth in the northeast Pacific subarctic. Nature, 331, 341343.

Martin, R.V., D.J. Jacob, R.M. Yantosca, M. Chin, and P. Ginoux, 2003: Global and regional decreases in tropospheric oxidants from photochemical effects of aerosols. J. Geophys. Res., 108(D3), 4097, doi:10.1029/2002JD002622.

Mellor, G.L. and T. Yamada, 1974: A hierarchy of turbulence closure models for planetary boundary layers. J. Atmos. Sci., 31, 1791-1806.

Miller, R.L., I. Tegen, and J. Perlwitz, 2004: Surface radiative forcing by soil dust aerosols and the hydrologic cycle. J. Geophys. Res., 109, D04203, doi:10.1029/2003JD004085.

Morsi, S.A. and Alexander, 1972: An investigation of particle trajectories in two-phase flow systems. J. Fluid. Mech., 55, 193-208.

Owen, P.R., 1964: Saltation of uniform grains in air. J. Fluid. Mech., 20, 225-242.

Penner, J.E., M. Andreae, H. Annegarn, L. Barrie, J. Feichter, D. Hegg, A. Jayaraman, R. Leaitch, 
D. Murphy, J. Nganga, and G. Pitari, 2001: Aerosols: Their direct and indirect effects. J.T. Houghton, Y. Ding, D. Griggs, M. Noguer, P.J. van der Linden, X. Dai, K. Maskell and C.A. Johnson, Eds., Climate Change 2001: The Scientific Basis, Contribution of Working Group I to the Third Assessment Report of the Intergovernmental Panel on Climate Change, Cambridge Univ. Press., New York, chapter 5, 289348.

Prospero, J.M. and T.N. Carlson, 1972: Vertical and areal distribution of Saharan dust over the western equatorial North Atlantic ocean. $J$. Geophys. Res., 77, 5255-5265.

, P. Ginoux, O. Torres, S.E. Nicholson, and T.E. Gill, 2002: Environmental characterization of global sources of atmospheric soil dust identified with the Nimbus 7 total ozone mapping spectrometer (TOMS) absorbing aerosol product. Rev. Geophys., 40, 1002, doi:10.1029/2000RG000095.

Sakai, T., T. Nagai, M. Nakazato, Y. Mano, and T. Matsumura, 2003: Ice clouds and Asian dust studied with lidar measurements of particle extinction-to-backscatter ratio, particle depolarization, and water-vapor mixing ratio over Tsukuba. Applied Optics, 42, 7103-7116.

Sassen, K., 2002: Indirect climate forcing over the western US from Asian dust storms. Geophys. Res. Lett., 29, doi:10.1029/2001GL014051. , P.J. DeMott, J.M. Prospero, and M.R. Poellot, 2003: Saharan dust storms and indirect aerosol effects on clouds: CRYSTAL-FACE results. Geophys. Res. Lett., 30, 1633, doi:10.1029/ 2003GL017371.

Seinfeld, J.H. and S.N. Pandis, 1997: Atmospheric chemistry and physics: From air pollution to climate change, A Wiely-Interscience publication, New York, NY, 1326pp.

Shao, Y., 2000: Physics and Modelling of Wind Erosion, Vol. 23 of Atmospheric and oceanographic sciences library, Kluwer Academic Press, Dordrecht, the Netherlands, 393pp.

and L.M. Leslie, 1997: Wind erosion prediction over the Australian continent. J. Geophys. Res., 102, 30091-30105.

and H. Lu, 2000: A simple expression for wind erosion threshold friction velocity. $J$. Geophys. Res., 105, 22437-22443.

, M.R. Raupach, and P.A. Findlater, 1993: Effect of saltation bombardment on the entrainment of dust by wind. J. Geophys. Res., 98, 12719-12726.

, — dicting aeolian sand drift and dust entrainment on scales from paddock to region. Aust. J. Soil. Res., 34, 309-342.
Shibata, K., H. Yoshimura, M. Ohizumi, M. Hosaka, and M. Sugi, 1999: A simulation of troposphere, stratosphere and mesosphere with an MRI/JMA98 GCM. Pap. Meteor. Geophys., 50, $15-53$.

Slinn, W.G.N., 1984: Precipitation scavenging. Atmospheric Science and Power Production, Vol. DOE/TIC-27601 (DE84005177), Office of Health and Environmental Research, U.S. Department of Energy, Washington, DC, chapter 11, 466-532.

Sokolik, I.N. and O.B. Toon, 1999: Incorporation of mineralogical composition into models of the radiative properties of mineral aerosol from UV to IR wavelengths. J. Geophys. Res., 104, 9423-9444.

Staniforth, A. and J. Côté, 1991: Semi-Lagrangian integration schemes for atmospheric modelsa review. Mon. Wea. Rev., 119, 2206-2223.

Swap, R., M. Garstang, S. Greco, R. Talbot, and P. Kållberg, 1992: Saharan dust in the Amazon Basin. Tellus, 44B, 133-149.

Takemura, T., H. Okamoto, Y. Murayama, A. Numaguti, A. Higurashi, and T. Nakajima, 2000: Global three-dimensional simulation of aerosol optical thickness distribution of various origins. J. Geophys. Res., 105, 17853-17873.

Takeuchi, K. and J. Kondo, 1981: Chihyo ni chikai taiki. Vol. 1 of Taiki kagaku kouza, Tokyo daigaku shuppankai, Tokyo, Japan, 226pp (in Japanese).

Tanaka, T.Y., K. Orito, T.T. Sekiyama, K. Shibata, M. Chiba, and H. Tanaka, 2003: MASINGAR, a global tropospheric aerosol chemical transport model coupled with MRI/JMA98 GCM: Model description. Pap. Meteor. Geophys., 53, 119138.

Tegen, I. and I. Fung, 1994: Modeling of mineral dust in the atmosphere: Sources, transport, and optical thickness. J. Geophys. Res., 99, 22897-22914.

and - 1995: Contribution to the atmospheric mineral aerosol load from land surface modification. J. Geophys. Res., 100, 1870718726.

, S.P. Harrison, K. Kohfeld, I.C. Prentice, M. Coe, and M. Heimann, 2002: Impact of vegetation and preferential source areas on global dust aerosol: Results from a model study. J. Geophys. Res., 107(D21), 4576, doi:10.1029/2001JD000963.

, I., M. Werner, S.P. Harrison, and K.E. Kohfeld, 2004: Relative importance of climate and land use in determining present and future global soil dust emission. Geophys. Res. Lett., 31, L05105, doi:10.1029/2003GL019216.

Wang, Z., I. Uno, and H. Akimoto, 2002: Neutraliza- 
tion of soil aerosol and its impact on the distribution of acid rain over east Asia: Observed evidence and simulation. J. Geophys. Res., 107, 4389, doi:10.1029/2001JD001040.

Webb, R.W., C.E. Rosenzweig, and E.R. Levine, 2000: Global soil texture and derived water-holding capacities (webb et al.) data set, Available online [http://www.daac.ornl.gov] from Oak Ridge National Laboratory Distributed Active Archive Center, Oak Ridge, Tennessee, U.S.A.

Werner, M., I. Tegen, S.P. Harrison, K.E. Kohfeld, I.C. Prentice, Y. Balkanski, H. Rodhe, and C. Roelandt, 2002: Seasonal and interannual variability of the mineral dust cycle under present and glacial climate conditions. $J$. Geophys. Res., 107(D24), 4744, doi:10.1029/ 2002JD002365.

Wilson, M. and A. Henderson-Sellers, 1985: A global archive of land cover and soils data for use in general circulation climate models. Journal of Climatology, 5, 119-143.

Woodward, S., 2001: Modeling the atmospheric life cycle and radiative impact of mineral dust in the Hadley Centre climate model. J. Geophys. Res., 106, 18155-18166.

Zender, C.S., H. Bian, and D. Newman, 2003a: Mineral Dust Entrainment and Deposition (DEAD) model: Description and 1990s dust climatology. J. Geophys. Res., 108(D14), 4416, doi:10.1029/2002JD002775.

— , D. Newman, and O. Torres, 2003b: Spatial heterogeneity in aeolian erodibility: Uniform, topographic, geomorphic, and hydrologic hypotheses. J. Geophys. Res., 108(D17), 4543, doi:10.1029/2002JD003039.

Zobler, L., 1986: A world soil file for global climate modeling, NASA Tech. Memo. 87802, NASA, 33pp. 